\title{
Cold-formed steel channel sections under end-two-flange loading condition: design for edge-stiffened holes, unstiffened holes and plain
}

\author{
webs \\ Asraf Uzzaman ${ }^{\mathrm{a}}$, James B.P Lim ${ }^{\mathrm{b}}$, David Nash ${ }^{\mathrm{a}}$ and Krishanu Roy \\ a Department of Mechanical and Aerospace Engineering, The University of Strathclyde, 75 Montrose Street, Glasgow G1 1XJ \\ b Department of Civil and Environmental Engineering, University of Auckland, New Zealand
}

\begin{abstract}
In cold-formed steel (CFS) channel sections, web holes are becoming increasingly popular. Such holes, however, result in the sections becoming more susceptible to web crippling, especially under concentrated loads applied near the web holes. Traditional web holes are normally punched or bored and are unstiffened. Recently, a new generation of CFS channel sections with edge-stiffened web holes has been developed by the CFS industry and is being widely used. However, no research is available in the literature which investigated the web crippling strength of CFS channel sections with edgestiffened circular web holes under the end-two-flange (ETF) loading conditions. A combination of experimental tests and non-linear FEA were used to investigate the effect of such stiffened holes on web crippling behaviour under ETF loading conditions. The results of 30 web crippling tests are presented. Non-linear FE models are described, and the results are compared against the laboratory test results; a good agreement was obtained in terms of both the strength and failure modes. The results indicate that the stiffened holes can significantly improve the web crippling strength of CFS channel sections. A parametric study involving 1116 FEA was then performed, covering the effect of different hole sizes, edge-stiffener lengths and fillet radii, length of the bearing plates and position of holes in the web. Finally, design recommendations in the form of web crippling strength reduction factors are proposed, that are conservative to both the experimental and FE results.
\end{abstract}




\section{Keywords}

Cold-formed steel; Web crippling; Channel section; Edge-stiffened web holes; unstiffened web holes, Circular web hole; Finite element analysis

\section{Nomenclature}

A Web holes ratio;

a Diameter of circular web holes;

$b_{f} \quad$ Overall flange width of section;

$b_{l} \quad$ Overall lip width of section;

COV Coefficient of variation;

$d \quad$ Overall web depth of section;

E Young's modulus of elasticity;

FEA Finite element analysis;

$h \quad$ Depth of the flat portion of the web;

$L \quad$ Length of the specimen;

$N \quad$ Length of the bearing plate;

$P \quad$ Experimental and finite element ultimate web crippling load per web;

$P_{\text {EXP }} \quad$ Experimental ultimate web crippling load per web;

$P_{\text {FEA }} \quad$ Web crippling strength per web predicted from finite element (FEA);

$r_{\mathrm{q}} \quad$ Inside fillet radius between web and hole edge-stiffener;

$r_{\mathrm{i}} \quad$ Inside fillet radius of section;

ROSH Reduction factor for edge-stiffened holes offset to the bearing plates

$R_{C S H} \quad$ Reduction factor for edge-stiffened holes down the bearing plates

$R_{P(O S H)} \quad$ Proposed reduction factor for edge-stiffened holes offset to the bearing plates 


\begin{tabular}{|ll|}
\hline$R_{P(\mathrm{CSH})}$ & Proposed reduction factor for edge-stiffened holes down the bearing plates \\
$t$ & Thickness of the section; \\
$q$ & Length of web holes edge-stiffener; \\
$Q$ & Web holes edge-stiffener length ratio; \\
$x$ & Horizontal clear distance of the web holes to the near edge of the bearing plate; \\
$\mathrm{X}$ & Web holes distance ratio; \\
$\sigma_{0.2}$ & Static $0.2 \%$ proof stress; and \\
$\sigma_{u}$ & Static ultimate tensile strength.
\end{tabular}




\section{Introduction}

Web holes are increasingly used in cold-formed steel (CFS) members to facilitate ease of services in buildings. In such members, web crippling can occur at points of concentrated loads [1] and is also influenced by the size and position of the holes. Plain CFS channel sections, as shown in Fig.1 (a), often require web holes for ease of installation of services [2]. Such holes are usually pre-punched or bored unstiffened web holes (see Fig.1 (b)). A new generation of CFS channel section with edge stiffened holes was recently developed by the CFS industry [3]. Fig.1 (c) shows a photograph of a CFS channel section with an edge-stiffened circular hole. As can be seen, the web holes are edge-stiffened through a continuous edge stiffener/lip around the perimeter of the hole. However, research on CFS channel sections with such edge stiffened holes is limited.

Yu [4] described a study on CFS channel sections having web holes that are edgestiffened. The numerical study described considered only bending; it was found that edgestiffened circular holes can improve the strength of CFS channel sections by an average of $14 \%$, compared to that of a plain channel section. In another numerical study, Grey and Moen [5] presented procedures for approximating the elastic critical buckling load (or moment) of CFS channel section due to the presence of edge-stiffened holes, without the need for eigenvalue FEA. More recently, Uzzaman et al. [6] presented tests and FEA results on the web crippling strength of CFS channel sections with edge-stiffened circular web holes under the interior-one-flange (IOF) and end-one-flange (EOF) loading conditions (as shown in Fig.2).

In the literature, significant work has been reported on the reduction in strength of channel sections having such unstiffened circular holes by Uzzaman et al. [7-10] and Lian et al. [11-14] covering web crippling. They proposed design recommendations in the form of web crippling strength reduction factor equations for channel sections under the interior-flange (IOF), end-one-flange (EOF), interior-two-flange (ITF) and end-two- 
flange (ETF) loading conditions. Yu and Davis [15], Sivakumaran and Zielonka [16], LaBoube et al. $[17,18]$ and Chung $[19,20]$ also reported research on the web crippling of channel section with unstiffened web holes. Research using the Direct Strength Method (DSM) and Generalized Beam Theorem (GBT), have also been reported in the literature [21-29] to investigate the web crippling strength of CFS channel sections. However, none of these investigations considered the effect of edge-stiffened web holes on web crippling strength of CFS channel sections. In terms of aluminium sections, Zhou and Young [30] conducted a series of tests and numerical investigations on web crippling square hollow sections, again with unstiffened web holes.

No experimental work in the literature has been reported for CFS channel sections with edge-stiffened web holes when subject to web crippling under ETF loading condition. Furthermore, current design guidance i.e. the American Iron and Steel Institute (AISI) [31], Eurocode-3 [32] and the Australian and New Zealand Standards (AS/NZS) [33] do not include direct guidance for CFS channel sections with edge-stiffened web holes under web crippling. The limitations of existing design code procedures for CFS members with edge-stiffened web holes can affect the design flexibility and decreases the reliability of cold-formed products in the modern construction industry.

In this paper, a combination of experimental investigation and non-linear FEA are used to investigate the effect of edge-stiffened circular web holes on the web crippling strength of CFS channel sections for the ETF loading condition (see Fig.3). As can be seen in Fig.3, web holes can either be located with an offset distance to the edge bearing plates or down the bearing plates, to be referred to in this paper as offset or down, respectively. Both cases of web holes are considered. The general purpose finite element program ANSYS [34] was used for the numerical investigation. The finite element model (FEM) included material non-linearities. The results of the finite element analysis were verified against the laboratory test results. Both the failure loads as well as the modes of 
failure predicted from the FEA were in good agreement with the laboratory test results. The FEM was then used for the purposes of a parametric study of the effect of different web hole sizes, edge-stiffener lengths and fillet radii, and the position of holes in the web. The results indicate that the edge-stiffened circular holes can significantly improve the web crippling strength of CFS channel sections. Based on the test data and the numerical results obtained from this study, an extensive statistical analysis was performed. For channel sections with edge-stiffened web holes, design recommendations in the form of web crippling strength reduction factor equations are proposed, which are conservative when compared with the experimental and finite element results.

\section{Experimental investigation}

\subsection{Test specimens}

A test programme was conducted on lipped channel sections, as shown in Fig.4, subjected to web crippling under ETF loading conditions. The test specimens comprised two different section sizes, having nominal thicknesses $(t)$ ranging from $2.0 \mathrm{~mm}$ to 2.5 $\mathrm{mm}$; the nominal depth $(d)$ of the webs ranged from $240 \mathrm{~mm}$ to $290 \mathrm{~mm}$; the nominal flange width $\left(b_{f}\right)$ for both sizes is $45 \mathrm{~mm}$. All holes had a nominal diameter $(a)$ of 140.0 $\mathrm{mm}$ and an edge-stiffener length $(q)$ of $13 \mathrm{~mm}$; the radius $\left(r_{q}\right)$ between the web and edgestiffener was $3.0 \mathrm{~mm}$; corner radius between web and flange $\left(r_{i}\right)$ was $3.0 \mathrm{~mm}$.

The test programme considered both webs having unstiffened circular holes and webs having edge-stiffened circular holes. Channel sections with no circular web holes (i.e. plain webs) were also tested, in order that the strength reduction can be determined experimentally. The ratio of the diameter of the circular holes to the depth of the flat portion of the webs $(a / h)$ were 0.6 and 0.5 for the C240 and C290 section, respectively.

All the test specimens were fabricated with web holes located at the mid-depth of the webs. In practice, web holes can be punched either down the bearing plates or with 
offset distance to the bearing plates. Therefore, both web holes position were considered into the web. The web holes were punched and the edge stiffeners were pressed as part of the manufacturing process [4].

The specimen lengths $(L)$ used were according to the AISI Specification [31, 35]. The distance from the edge of the bearing plate to the end of the member was set to be 1.5 times the overall depth of the web (d) rather than 1.5 times the depth of the flat portion of the web $(h)$, the latter being the minimum specified in the specification. The bearing plates were fabricated using with high strength steel having a thickness of $25 \mathrm{~mm}$. Three lengths of bearing plates $(N)$ were used: $50 \mathrm{~mm}, 75 \mathrm{~mm}$ and $100 \mathrm{~mm}$.

\subsection{Specimens labelling}

Table 1 and Table 2 show the measured test specimen dimensions for ETF condition, using the nomenclature defined in Fig.4. In Table 1 and Table 2 the specimens were labelled such that the loading condition, the nominal dimension of the specimen and the length of the bearing, as well as the ratio of the diameter of the holes to the depth of the flat portion of the webs $(a / h)$, could be identified from the label. For example, the labels "ETF-240x45x15-N50-NH" define the following specimens:

- $\quad$ The first three letters indicate the web crippling loading condition used i.e. end-two-flange (ETF)

- The symbols $d \times b_{\mathrm{f}} \times b_{1}$ refer to the nominal dimensions of the specimens in millimetres i.e. $240 \times 45 \times 15$ means $d=240 \mathrm{~mm} ; b_{\mathrm{f}}=45 \mathrm{~mm}$; and $b_{1}=13 \mathrm{~mm}$

- The notation "N50" indicates the length of bearing in millimetres $(N=50 \mathrm{~mm})$

• $\quad$ The last three notations "NH", "USCH", "ESCH" "USOH", and "ESOH" indicates the web holes cases. "NH" represents the no web hole case, "USOH" and "ESOH" represents a web having a hole offset from the bearing plates are unstiffened and edge-stiffened, respectively, "USCH" and "ESCH" represents 
a web having a hole down the bearing plates are unstiffened and edge-stiffened, respectively,

\subsection{Material properties}

Tensile coupon tests were carried out to determine the material properties of the channel specimens. The tensile coupons were taken from the centre of the web plate in the longitudinal direction of the untested specimens. The tensile coupons were prepared and tested according to the British Standard for Testing and Materials for the tensile [36] testing of metals using $12.5 \mathrm{~mm}$ wide coupons of a gauge length $50 \mathrm{~mm}$. The coupons were tested in an MTS displacement controlled testing machine using friction grips. Two strain gauges and a calibrated extensometer of $50 \mathrm{~mm}$ gauge length were used to measure the longitudinal strain. The average material properties obtained from tensile coupon tests are summarised in Table 3, which includes the measured static $0.2 \%$ proof stress $\left(\sigma_{0.2}\right)$ and the static tensile strength $\left(\sigma_{u}\right)$.

\subsection{Test rig and procedure}

The specimens were tested under the ETF loading condition specified in the AISI Specification $[31,35]$, as shown in Fig.5. For the ETF loading condition, two identical bearing plates of the same width were positioned at the end of each specimen, respectively. Hinge supports were simulated by two half rounds in the line of action of the force. A servo-controlled Tinius-Olsen testing machine was used to apply a concentrated compressive force to the test specimens. Displacement control was used to drive the hydraulic actuator at a constant speed of $0.05 \mathrm{~mm} / \mathrm{min}$ for all the test specimens. The load or reaction force was applied by means of bearing plates. The bearing plates were fabricated using high strength steel. All the bearing plates were machined to specified dimensions, and the thickness was $25 \mathrm{~mm}$. In the experimental investigation, three different lengths of bearing plates $(N)$ were used, namely, $50 \mathrm{~mm}, 75 \mathrm{~mm}$ and 100 
$\mathrm{mm}$. The flanges of the channel section specimens were not bolted to the bearing plates during testing. Fig.6 (a) and Fig.7 (a) shows the photograph of the test setup,

\subsection{Test results}

A total of 30 specimens were tested under ETF condition. The experimental ultimate web crippling loads per web $\left(P_{\mathrm{EXP}}\right)$ for the offset and down web holes are given in Table 1 and Table 2, respectively. The typical failure mode of web crippling of the specimens is shown in Fig.8.

It was observed that the out-of-plane deformation of the webs occurred gradually at the early stage of loading and continued to increase until failure occurred. The failure pattern was symmetrical and failure occurred due to the formation of a local yield zone under the bearing plate. Moreover, because of the presence of edge-stiffeners around the hole, the channel sections were stiff and lateral displacement of the webs were small. The deformation due to the web crippling of channel sections was higher for the case of web holes underneath the bearing plate, when compared to the case of web holes offset to the bearing plate. This comparison shows the case of web hole down the bearing plate decreases the web crippling resistance.

Fig.9 shows a typical example of the load-defection curve obtained from the experiments and FEA for a specimen having both web holes and without web holes. As the load increases, a linear behaviour was seen initially until the yield point, in the line up to point A. The maximum stress occurred in the bottom corner between the flange and web. Beyond point A, the load-displacement curve shown the non-linearity as the bottom portion of the channel sections starts to deform locally which indicated the initial stages of buckling. The load continues to increase due to the support provided by the remaining portion of the channel section, shown by line $\mathrm{AB}$ of the load-displacement curve. Beyond point $\mathrm{B}$, the channel section began to collapse with reduced overall load carrying capacity due to the channel section reached the ultimate stress. Beyond the yield point, plasticity 
began to spread through the channel section, and hence, plastic hinges were formed at the web mid-height. Beyond the maximum load (point B), the channel section failed gradually as shown by line $\mathrm{BC}$ of the load-displacement curve. Beyond the maximum load (point B), post-buckling strength of the channel section was achieved.

The web crippling strengths for channel sections with web holes divided by that of sections without web holes, which is the strength reduction percentage $(R)$, was used to quantify the degrading influence of the web holes on the web crippling strengths.

It can be seen from Table 1 for the offset web holes, as a result of the unstiffened holes, the web crippling strength reduced by $33.6 \%$ and $18.7 \%$ for section $240-\mathrm{N} 100$ and 290-N75, respectively; these are the maximum and minimum strength reductions. Conversely, through use of edge-stiffened holes, the web crippling strength increased by $7.1 \%$ and $7.5 \%$ for the same sections, respectively, relative to the strength of a plain section without holes. It can be seen from Table 2 for down web holes, as a result of the unstiffened holes, the web crippling strength reduced by $50.0 \%$, and $40.5 \%$ for section 240-N50 and 290-N75, respectively; these are the maximum and minimum strength reductions. Conversely, through use of edge-stiffened holes, the web crippling strength increased by $37.9 \%$ and $16.8 \%$ for the same sections, respectively, relative to the strength of a plain section without holes.

\section{Numerical Investigation}

\subsection{General}

The non-linear elasto-plastic general purpose finite element program ANSYS [34] was used to simulate the channel sections with and without holes subjected to web crippling. The bearing plates, the channel section with circular holes and the interfaces between the bearing plates and the channel section have been modelled. In the finite element model, the measured cross-section dimensions and the material properties 
obtained from the tests were used. The model was based on the centreline dimensions of the cross-sections. Specific modelling issues are described in the following subsection.

\subsection{Geometry and material properties}

The full test setup was modelled, as shown in Fig.6 (b) and Fig.7 (b). The dimensions of the channel sections modelled are given in Table 1 and Table 2 for offset and down web holes, respectively. Contact pairs are defined between the bearing plate and the CFS channel section.

The value of Young's modulus was $203 \mathrm{kN} / \mathrm{mm}^{2}$ and Poisson's ratio was 0.3 . The material non-linearity was incorporated in the finite element model by specifying 'true' values of stresses and strains. The plasticity of the material was determined by a mathematical model, known as the incremental plasticity model; the true stress $\left(\sigma_{\text {true }}\right)$ and plastic true strain $\left(\varepsilon_{\text {true }}\right)$. The stress-strain curves were directly obtained from the tensile tests and converted into true stress- true plastic strain curves using equation 1 and equation 2, as specified in the ANSYS manual [34],

$$
\begin{aligned}
& \sigma_{\text {true }}=\sigma(1+\varepsilon) \\
& \varepsilon_{\text {true }(p l)}=\ln (1+\varepsilon)
\end{aligned}
$$

where $E$ is the Young's Modulus, $\sigma$ and $\varepsilon$ are the engineering stress and strain, respectively in ANSYS manual [34].

The plastic deformation of the corners due to the roll-forming process was not considered in the FEA model. Schafer et al. [37] showed that the effect of residual stress on CFS is to offset by that of increasing the yield stress in the corner regions. This was also confirmed in a web crippling computational study carried out by Natario et al. [22]. With respect to geometric imperfections, Sundararajah et al. [26-28] and Natario et al. [22] investigated this effect the ultimate web crippling capacities for CFS lipped channel sections under the two-flange loading condition and found that the initial geometric 
imperfections have little impact on web crippling strength. However, the sensitivity of imperfections may be larger for the web crippling strength if the corner radius is very small or zero, e.g. for extruded aluminium sections. This study though has been limited to the manufactures standard $3 \mathrm{~mm}$ corner radius and so the effects of residual stresses and imperfections were not considered in the FE model developed.

\subsection{Element type and mesh sensitivity}

Fig.6 (b) and Fig.7 (b) shows details of a typical finite element mesh of the channel section and the bearing plate. The effect of different element sizes in the cross-section of the channel section was investigated to provide both accurate results and reduced computation time. Depending on the size of the section, the finite element mesh sizes ranged from $3 \mathrm{~mm} \times 3 \mathrm{~mm}$ (length by width) to $5 \mathrm{~mm} \times 5 \mathrm{~mm}$.

It is necessary to finely mesh the corners of the channel section due to the transfer of stress from the flange to the web. Nine elements were used around the inside corner radius that forms the bend between the flange and web. Three elements were used at the rounded corners between the flange and lip of the section. The number of elements was chosen so that the aspect ratio of the elements was as close to one as possible. Where hole was modelled, finer mesh sizes were used around the web holes. Mesh sensitivity analyses were performed to verify the number of elements. Hofmeyer [38-39] reported similar modelling technique for cross-section crushing behaviour of hat sections.

The channel sections were modelled using the 4-noded shell element SHELL181. The bearing plates were modelled using the eight-noded solid element SOLID45. CONTA173 and TARGET170 elements were used for modelling contact between the flanges and the load bearing plates. 


\subsection{Loading and boundary conditions}

The interface between the bearing plate and the CFS channel section were modelled using the surface-to-surface contact option. The bearing plate was the target surface, while the CFS channel section was the contact surface. The two contact surfaces were not allowed to penetrate each other. Ting et al. [40] and Roy et al. [41-43] used the similar modelling technique for back-to-back and face-to-face CFS channels.

The vertical load applied to the channel sections in the laboratory tests was modelled using displacement control; an imposed displacement is applied to the nodes of the top bearing plate where the vertical load is applied. The top bearing plate was restrained against all degrees of freedom, except for the translational degree of freedom in the vertical direction.

\subsection{Verification of the finite element model}

In order to validate the finite element model, the experimental failure loads were compared against the failure load predicted by the finite element analysis. The main objective of this comparison was to verify and check the accuracy of the finite element model. A comparison of the test results $\left(P_{\mathrm{EXP}}\right)$ with the numerical results $\left(P_{\mathrm{FEA}}\right)$ of web crippling strengths per web is shown in Table 4 and Table 5 for the offset and down web holes, respectively. It can be seen that good agreement has been achieved between both results for all specimens. The mean value of the $P_{\mathrm{EXP}} / P_{\mathrm{FEA}}$ ratio is 0.99 and 1.00 with the corresponding coefficient of variation (COV) of 0.04 and 0.05 for the offset and down web holes, respectively. A maximum difference of $7 \%$ and $9 \%$ was observed between the experimental and the numerical results for the specimen ETF290x45x15-N100-NH and ETF290x45x15-N50-ESCH, respectively. The web deformation curves predicted by finite element analysis were compared with the experimental curves, as shown in Fig.9 for plain, unstiffened and edge-stiffened web holes. 
The web crippling failure mode observed from the tests has been also verified by the finite element model for the offset and down web holes, as shown in Fig.8. It is shown that good agreement is achieved between the experimental and finite element results for both the web crippling strength and the failure mode. Fig.8 shows the Von Mises stress distribution after the collapse of the specimens. As the load increases, the maximum stress at a point reached its yield point. The initial yielding was formed in the bottom corner between the flange and web. Beyond this point, a hinge was formed at the web midheight. Due to the presence of unstiffened web holes, the ultimate load reduces. The finite element models showed that stresses developed around the web holes and then away from the web holes. Similar stress distributions can be seen for both specimens with edgestiffened web hole and plain section. A parametric study is performed in the following section to obtained optimized dimensions of the web holes profiles for the CFS channel sections.

\section{Parametric Study}

The finite element model developed closely predicted the web crippling behaviour of the channel sections with unstiffened and edge-stiffened web holes. Using this validated model, parametric studies were carried out to study the effects of web holes sizes, location of the holes and length of the edge-stiffener on the web crippling strengths of channel sections subjected to web crippling.

A total of 27 specimens were analysed to investigate the effects of the corner radius between web and flange $\left(r_{i}\right)$ on web crippling strength reduction factor $\left(R_{O S H}\right)$ for offset web holes. For this study, channel section C240 was used, having a nominal depth of 240 $\mathrm{mm}$. Three different lengths of bearing plates of $50 \mathrm{~mm}, 75 \mathrm{~mm}$ and $100 \mathrm{~mm}$ were considered. The ratio $(A)$ of the diameter of the holes $(a)$ to the depth of the flat portion of the webs $(h)$ were $0.4,0.6$ and 0.8 . Three different corner radii between web and flange 
$\left(r_{i}\right) 2 \mathrm{~mm}, 4 \mathrm{~mm}$ and $6 \mathrm{~mm}$ were considered. The ratio $(X)$ of the distance of the web holes $(x)$ to the depth of the flat portion of the webs $(h)$ was 0.4 . The inside corner radius between web and hole edge-stiffener was $4 \mathrm{~mm}$. The ratio $(Q)$ of the length of stiffener $(q)$ to the depth of the flat portion of the webs $(h)$ was 0.04 . For each series of specimens, the web crippling strength of the sections without the web holes was obtained. Thus, the strength reduction factor $\left(R_{O S H}\right)$ is the ratio of the web crippling strengths for CFS channel section with offset edge-stiffened web holes divided by the channel sections without the web holes. For the range of geometry investigated, it can be seen from Fig. 10 that $r_{i}$ has less than $1 \%$ effect on the strength reduction factor $\left(R_{O S H}\right)$. The effect of the corner radius was therefore not considered in the parametric study and the strength reduction factor equations.

Uzzaman et al. [7-10], Lian et al. [11-14] and Yousefi et al. [44-46] have previously shown that the ratios of $a / h, x / h$ and $N / h$ are the primary parameters influencing the web crippling behaviour of the channel sections with unstiffened web holes. The web crippling strength predicted was influenced primarily by the ratio of the hole depth to the flat portion of the web, $a / h$, the ratio of the bearing length to the flat portion of the web, $N / h$ and the location of the hole as defined by the distance of the hole from the edge of the bearing divided by the flat portion of the web, $x / h$. For the case of edge-stiffened web holes, the ratio of the edge-stiffener length to the flat portion of the web, $q / h$ and the ratio of the inside fillet radius between web and hole edge-stiffener to the thickness of the section, $r_{q} / t$ were also shown to influence the web crippling strength. In order to find the effect of $a / h, x / h, r_{q} / t$ and $q / h$ on web crippling strength for offset web holes and the effect of $a / h, N / h, r_{q} / t$ and $q / h$ on web crippling strength for down web holes, two separate parametric studies were carried out considering the web holes sizes, the cross-section thicknesses, lengths of the bearing plate, locations of the holes, corner radii between web and hole edge-stiffener and lengths of web holes edge-stiffener. 
In this study channel section, C240 was used, having a nominal depth of $240 \mathrm{~mm}$. Three different lengths of bearing plates $50 \mathrm{~mm}, 75 \mathrm{~mm}$ and $100 \mathrm{~mm}$ were considered. The ratio (A) of the diameter of the holes $(a)$ to the depth of the flat portion of the webs (h) were $0.2,0.4,0.6$ and 0.8 . The ratio $(\mathrm{X})$ of the distance of the web holes $(x)$ to the depth of the flat portion of the webs $(h)$ were $0.2,0.4$ and 0.6. The inside corner radii between web and hole edge-stiffener were $2 \mathrm{~mm}, 4 \mathrm{~mm}$ and $6 \mathrm{~mm}$. The ratio $(Q)$ of the length of stiffener $(q)$ to the depth of the flat portion of the webs $(h)$ were $0.04,0.06$ and 0.08. For each series of specimens, the web crippling strengths of the sections without the web holes and unstiffened web holes were obtained. Thus, the strength reduction factor $\left(R_{O S H}\right)$ is the ratio of the web crippling strengths for CFS channel section with offset edgestiffened web holes divided by the channel sections without the web holes. The ratio of the web crippling strengths for CFS channel sections with down edge-stiffened web holes and divided by the channel sections without the web holes, gives the strength reduction factor $\left(R_{C S H}\right)$. Both strength reduction factors were used to quantify the degrading influence of the web holes on the web crippling strengths.

It can be seen in Fig.11, Fig.12, Fig.13 and Fig.14 the specimens were labelled according to the analysis type. For example the label 'T6-N75-X0.2-A0.4-Rq2' \& 'T6Q0.06-X0.2-N75-A0.4' stands for thickness (T6 means $6 \mathrm{~mm}$ thickness), bearing plate length (N75 means $75 \mathrm{~mm}$ length of the bearing plate), web holes distance ratio (X0.2 means $x / h=0.2$, web holes ratio (A0.4 means $a / h=0.4)$, edge-stiffener length ratio (Q0.06 means $q / h=0.06)$ and edge-stiffener fillet radius ratio (Rq2 means $\left.r_{q}=2 \mathrm{~mm}\right)$.

\subsection{Effect of $a / h, x / h, r_{q} / t$ and $q / h$ on web crippling strength reduction factor $\left(R_{O S H}\right)$ for offset web holes}

A total of 837 specimens were analysed in the parametric study to investigate the effect of the ratios $a / h, x / h, r_{q} / t$ and $q / h$. The cross-section dimensions, as well as the web crippling strengths $\left(\mathrm{P}_{\mathrm{FEA}}\right)$ per web predicted from the FEA, are summarised in Table 6, 
Table 7 and Table 8 for the thicknesses of $2 \mathrm{~mm}, 4 \mathrm{~mm}$ and $6 \mathrm{~mm}$, respectively. The effects of $a / h$ and $x / h$ ratio on the web crippling strength reduction factor are shown in Fig.11. It can be seen from Fig.11 (a) for the specimen T6-N50-X0.2 the web hole diameter ratio $\mathrm{a} / \mathrm{h}$ increases from 0.4 to 0.8 , the web crippling reduction factor decreases against the different length of the edge-stiffeners and fillet radius of the edge-stiffeners. Fig.11 (b) shows the effect of web holes distance ratio $x / h$ web crippling strength reduction factor for the specimens T6-Rq2-N50 where the results show the increase of web crippling strength reduction factor when web holes distance ratio $\mathrm{x} / \mathrm{h}$ increases from 0.2 to 0.6 against the different length of the edge-stiffeners and web holes diameter.

The effects of $r_{q} / t$ and $q / h$ on the web crippling strength reduction factor are shown in Fig.12. A slight increase of the strength reduction factor is observed when $r_{q} / t$ increases (see Fig.12 (a). Fig.12 (b) shows the effect of length of the edge-stiffeners ratio $q / h$ web crippling strength reduction factor for the specimens T6-N50-X0.2 where the results show the increase of web crippling strength reduction factor when length of the edge-stiffeners ratio $q / h$ increases from 0.04 to 0.08 against different edge-stiffeners fillet radius and web holes diameter.

4.2 Effect of $a / h, N / h, r_{q} / t$ and $q / h$ on web crippling strength reduction factor $\left(R_{O S H}\right)$ for down web holes

A total of 279 specimens were analysed in the parametric study to investigate the effect of the ratio $a / h, N / h, r_{q} / t$ and $q / h$. The cross-section dimensions, as well as the web crippling strengths $\left(\mathrm{P}_{\mathrm{FEA}}\right)$ per web predicted from the FEA, are summarised in Table 9. The effects of $a / h$ and $N / h$ ratio on the web crippling strength reduction factor are shown in Fig.13. It can be seen from Fig.13 (a) for the specimen T6-N50 the web hole diameter ratio $\mathrm{a} / \mathrm{h}$ increases from 0.4 to 0.8 , the web crippling reduction factor decreases against the different length of the edge-stiffeners and fillet radius of the edge-stiffeners. Fig.13 (b) shows the effect of bearing plate length ratio $N / h$ web crippling strength reduction 
factor for the specimens $\mathrm{T} 2-\mathrm{Rq} 2$ where the results show the increase of web crippling strength reduction factor when bearing plate length ratio $N / h$ increases from 0.22 to 0.44 against the different length of the edge-stiffeners and web holes diameter.

The effects of $r_{q} / t$ and $q / h$ on the web crippling strength reduction factor are shown in Fig.14. It can be seen from Fig.14 (a) for the specimen T6-Q0.04 where the results show the web crippling strength reduction factor increases when edge-stiffeners fillet radius ratio $r_{q} / t$ increases from 0.33 to 0.99 . Fig. 14 (b) shows the effect of length of the edge-stiffeners ratio $q / h$ web crippling strength reduction factor for the specimens T6N50 where the results show the increase of web crippling strength reduction factor when length of the edge-stiffeners ratio $q / h$ increases from 0.04 to 0.08 against different edgestiffeners fillet radius and web holes diameter.

\section{$5 \quad$ Reliability analysis}

The reliability of the CFS channel section design rules is evaluated using reliability analysis. The reliability index $(\beta)$ is a relative measure of the safety of the design. A target reliability index of 2.5 for CFS structural members is recommended as a lower limit in the NAS Specification [47]. The design rules are considered to be reliable if the reliability index is greater than or equal to 2.5 . The load combination of $1.2 \mathrm{DL}+$ 1.6LL as specified in the American Society of Civil Engineers Standard [48] was used in the reliability analysis, where DL is the dead load and LL is the live load. The statistical parameters are obtained from Table F1 of the NAS Specification [47] for compression members, where $M_{m}=1.10, F_{m}=1.00, V_{M}=0.10$, and $V_{F}=0.05$, which are the mean values and coefficients of variation for material properties and fabrication factors.

The statistical parameters $P_{m}$ and $V_{P}$ are the mean value and coefficient of variation of load ratio are shown in Table 10 and Table 11, respectively. In calculating the reliability index, the correction factor in the NAS Specification was used. Reliability 
analysis is detailed in the NAS Specification. In the reliability analysis, a constant resistance factor $(\phi)$ of 0.85 was used. It is shown in Table 10 and Table 11 that the reliability index $(\beta)$ is greater than the target value of 2.5 .

\section{Proposed strength reduction factors}

Evaluation of the experimental and the numerical results shows that the ratios $a / h$, $x / h, r_{q} / t$ and $q / h$ for offset web holes and the ratios $a / h, N / h, r_{q} / t$ and $q / h$ for down web hole are the primary parameters influencing the on web crippling strength reduction factors of the channel sections with edge-stiffened web holes. Therefore, based on both the experimental and the numerical results obtained from this study, two strength reduction factor equations $\left(R_{\mathrm{p}(\mathrm{OSH})}\right.$ and $\left.R_{\mathrm{p}(\mathrm{CSH})}\right)$ are proposed using bivariate linear regression analysis for the offset and down web holes.

For the offset to the bearing plates web holes,

$R_{P(O S H)}=0.98-0.11\left(\frac{a}{h}\right)+0.01\left(\frac{x}{h}\right)+0.05\left(\frac{r_{q}}{t}\right)+0.41\left(\frac{q}{h}\right) \leq 1$

For the down the bearing plates web holes,

$$
R_{P(C S H)}=0.92-0.35\left(\frac{a}{h}\right)+0.12\left(\frac{N}{h}\right)+0.21\left(\frac{r_{q}}{t}\right)+0.22\left(\frac{q}{h}\right) \leq 1
$$

The limits for the reduction factor equations (3) and (4) are $h / t \leq 118$, are $N / h \leq 0.44$, $a / h \leq 0.8, q / h \leq 0.08, x / h \leq 0.6$, and $\theta \leq 90^{\circ}$.

\section{Comparison of the experiment and numerical results with the proposed reduction factor}

The values of the strength reduction factors $R_{O S H}$ and $R_{C S H}$ obtained from the experimental and the numerical results are compared with the values of the proposed strength reduction factor $R_{P(O S H)}$ and $R_{P(C S H)}$ calculated using Eqn. (3) and Eqn. (4), as 
plotted against the ratios $h / t$ in Fig.15 and Fig.16 for the offset and down web holes, respectively. Table 10 and Table 11 summarizes a statistical analysis to define the accuracy of the proposed design equations. The values of the proposed reduction factor are generally conservative and agree well with the experimental and the numerical results for ETF loading conditions. As can be seen, the proposed reduction factors are generally conservative and agree with the experiment and the numerical results for both load cases. The mean value of the web crippling reduction factor ratios are 1.00 and 1.00 with the corresponding $\mathrm{COV}$ of 0.06 and 0.06 , and reliability index $(\beta)$ of 2.81 and 2.78 for the offset and down web holes, respectively. Thus, the proposed strength reduction factor equations are able to predict the influence of the edge-stiffened web holes on the web crippling strengths of channel sections for the ETF loading condition.

\section{Conclusions}

Experimental and numerical investigations of lipped channel sections with plain, circular unstiffened and edge-stiffened web holes subjected to web crippling have been presented. Web holes located at the mid-depth of the web with a horizontal clear distance to the near edge of the bearing plate and down the bearing plates were considered. A series of tests were conducted on lipped channel sections with web holes subjected to the ETF loading condition. A total of 30 specimens were tested under the offset and down web holes. The channel specimens had a $0.2 \%$ proof stresses (yield stresses) of $268 \mathrm{MPa}$ and $328 \mathrm{MPa}$ for the two different section sizes.

For the offset web holes, it is shown that for the case of specimen ETF-240x45x 15 N50, the web crippling strength was reduced by $29.5 \%$ for the unstiffened holes. Similarly, for the same channel section, the web crippling strength was increased by 16.9 $\%$ for the edge-stiffened holes. For the down web holes, it is shown for the same channel 
section that the web crippling strength reduced by $50.0 \%$ for the unstiffened holes and strength increased by $37.9 \%$ for the edge-stiffened holes.

A finite element model that incorporated the geometric and the material nonlinearities has been developed and verified against the experimental results. The finite element model was shown to be able to closely predict the web crippling behaviour of the channel sections, both with and without web holes. Thereafter, a parametric study was carried out to study the effects of web holes sizes, location of the holes, length of the bearing plates, fillet radii of the edge-stiffener and length of the edge-stiffener on the web crippling strengths of the channel sections. A total of 1,116 models were analysed and it was shown that the ratios $a / h, x / h, r_{q} / t$ and $q / h$ for offset web holes and the ratios $a / h$, $N / h, r_{q} / t$ and $q / h$ for down web holes are the primary parametric relationships influencing the web crippling behaviour of the channel sections with edge-stiffened web holes.

Based on the available data obtained from the experimental and numerical investigations, web crippling strength reduction factor equations were proposed for offset and down web holes. Reliability analysis was performed to evaluate the reliability of the proposed strength reduction factors. It was shown that the proposed strength reduction factors are generally conservative and agree well with the experimental and numerical results. The proposed strength reduction factors are capable of producing reliable limit state design when calibrated with the resistance factor of $0.85(\phi=0.85)$.

\section{Acknowledgements}

The Authors would like to acknowledge Howick Ltd. for providing the test specimens. The experimental work was carried out by Wei Lin and Cong $\mathrm{Li}$, as part of their undergraduate research projects. The authors also wish to thank Ross Reichardt and Mark Byrami for their assistance in preparing the specimens and carrying out the experimental testing. 


\section{References}

[1] Rhodes J, Nash D. An investigation of web crushing behaviour in thin-walled beams. Thin-Walled Structures. 1998; 32:207-30.

[2] Lawson RM, Basta A, Uzzaman A. Design of stainless steel sections with circular openings in shear. Journal of Constructional Steel Research. 2015; 112:228-41.

[3] Howick. Floor Joist System. Auckland, New Zealand 2013.

[4] Yu C. Cold-formed steel flexural member with edge stiffened holes: Behavior, optimization, and design. Journal of Constructional Steel Research. 2012; 71:210-218.

[5] Grey CN, Moen CD. Elastic Buckling Simplified Methods for Cold-Formed Columns and Beams with Edge-Stiffened Holes. Proceedings of the Annual Stability Conference. Pittsburgh, PA: SSRC; 2011.

[6] Uzzaman A, Lim JBP, Nash D, Young B. Effects of edge-stiffened circular holes on the web crippling strength of cold-formed steel channel sections under one-flange loading conditions. Engineering Structures. 2017; 139:96-107.

[7] Uzzaman A, Lim JBP, Nash D, Rhodes J, Young B. Web crippling behaviour of coldformed steel channel sections with offset web holes subjected to interior-two-flange loading. Thin-Walled Structures. 2012; 50:76-86.

[8] Uzzaman A, Lim JBP, Nash D, Rhodes J, Young B. Cold-formed steel sections with web openings subjected to web crippling under two-flange loading conditions-part I: Tests and finite element analysis. Thin-Walled Structures. 2012; 56:38-48.

[9] Uzzaman A, Lim JBP, Nash D, Rhodes J, Young B. Cold-formed steel sections with web openings subjected to web crippling under two-flange loading conditions-Part II: Parametric study and proposed design equations. Thin-Walled Structures. 2012; 56:7987. 
[10] Uzzaman A, Lim JBP, Nash D, Rhodes J, Young B. Effect of offset web holes on web crippling strength of cold-formed steel channel sections under end-two-flange loading condition. Thin-Walled Structures. 2013; 65:34-48.

[11] Lian Y, Uzzaman A, Lim JBP, Abdelal G, Nash D, Young B. Effect of web holes on web crippling strength of cold-formed steel channel sections under end-one-flange loading condition - Part I: Tests and finite element analysis. Thin-Walled Structures. 2016; 107:443-52.

[12] Lian Y, Uzzaman A, Lim JBP, Abdelal G, Nash D, Young B. Effect of web holes on web crippling strength of cold-formed steel channel sections under end-one-flange loading condition - Part II: Parametric study and proposed design equations. Thin-Walled Structures. 2016; 107:489-501.

[13] Lian Y, Uzzaman A, Lim JBP, Abdelal G, Nash D, Young B. Web crippling behaviour of cold-formed steel channel sections with web holes subjected to interior-oneflange loading condition-Part I: Experimental and numerical investigation. Thin-Walled Structures. 2017; 111:103-12.

[14] Lian Y, Uzzaman A, Lim JBP, Abdelal G, Nash D, Young B. Web crippling behaviour of cold-formed steel channel sections with web holes subjected to interior-oneflange loading condition - Part II: parametric study and proposed design equations. ThinWalled Structures. 2017; 114:92-106.

[15] Yu WW, Davis CS. Cold-formed steel members with perforated elements. Journal of the Structural Division. 1973; 99:2061-77.

[16] Sivakumaran KS, Zielonka KM. Web crippling strength of thin-walled steel members with web opening. Thin-Walled Structures. 1989; 8:295-319.

[17] LaBoube RA, Yu WW, Deshmukh SU, Uphoff CA. Crippling Capacity of Web Elements with Openings. Journal of Structural Engineering. 1999; 125:137-41. 
[18] LaBoube RA, Yu WW, Langan JE. Cold-formed steel web with openings: Summary report. Thin-Walled Structures. 1997; 28:355-72.

[19] Chung KF. Structural perfomance of cold formed sections with single and multiple web openimgs. Part-1: Experimental investigation. The Structural Engineer. 1995; 73.

[20] Chung KF. Structural perfomance of cold formed sections with single and multiple web openimgs. Part-2: Design rules. The Structural Engineer. 1995; 73.

[21] Natario P, Silvestre N, Camotim D. Web crippling of beams under ITF loading A novel DSM-based design approach. Thin Walled Structures. 2016; 98 (part B):360-374.

[22] Natario P, Silvestre N, Camotim D. Web crippling failure using quasi-static FE models. Thin Walled Structures. 2014; 84:34-49.

[23] Natario P, Silvestre N, Camotim D. Localized web buckling analysis of beams subjected to concentrated loads using GBT. Thin Walled Structures. 2012; 61:27-41.

[24] Shanmuganathan G, Mahendran M. Experimental study of unlipped channel beams subject to web crippling under one flange load cases. Advanced Steel Construction. 2019; 15(2):165 172 .

[25] Heurkens RAJ, Hofmeyer H, Mahendran M, Snijder HH. Direct strength method for web crippling-Lipped channels under EOF and IOF loading. Thin Walled Structures. 2018; 123:126-141.

[26] Sundararajah L, Mahendran M, Keerthan P. Web crippling studies of SupaCee sections under two flange load cases. Engineering Structures. 2017; 153: 582-597.

[27] Sundararajah L, Mahendran M, Keerthan . Web crippling experiments of high strength lipped channel beams under one-flange loading. Journal of Constructional Steel Research. 2017; 138: 851-866. 
[28] Sundararajah L, Mahendran M, Keerthan . New design rules for lipped channel beams subject to web crippling under two-flange load cases. Thin Walled Structures. 2017; 119: 421-437.

[29] Bakker MCM, Stark JWB. Theoretical and experimental research on web crippling of cold-formed flexural steel members. Thin Walled Structures. 1994; 18(4): 261-290.

[30] Zhou F, Young B. Web crippling of aluminium tubes with perforated webs. Engineering Structures. 2010; 32:1397-410.

[31] AISI. Specifications for the Cold-Formed Steel Structural Members, Cold-Formed Steel Design Manual. Washington, D.C: American Iron and Steel Institute; 2016.

[32] Eurocode-3. BS EN 1993-1-3-Design of steel structures: Part 1.3: General rules Supplementary rules for cold-formed thin gauge members and sheeting. BS EN 1993-13:2006. Brussels, Belgium: European Committee for Standardization; 2006.

[33] AS/NZS. Australia/New Zealand Standard AS/NZS 4600 Cold-formed steel structures. Sydney: Australian/New Zealand Standard; 2005.

[34] ANSYS. User's manual, revision 17.0. Swanson Analysis System; 2017.

[35] AISI. Standard Test Method for Determining the Web Crippling Strength of ColdFormed Steel Beams. Washington DC, USA: American Iron and Steel Institute; 2013.

[36] EN-BS. 10002-1: 2001. Tensile testing of metallic materials. Method of test at ambient temperature. British Standards Institution2001.

[37] Schafer B.W., Li Z., Moen C.D., Computational modeling of cold-formed steel, Thin-Wall. Struct., 48 (2010) 752-762.

[38] Hofmeyer H. Cross-section crushing behaviour of hat-sections (Part I: Numerical modelling). Thin-Walled Structures. 2005; 43(8): 1143-1154. 
[39] Hofmeyer H. Cross-section crushing behaviour of hat-sections (Part II: Analytical modelling). Thin-Walled Structures. 2005; 43(8): 1155-1165.

[40] Ting TCH, Roy K, Lau HH, Lim JBP. Effect of screw spacing on behavior of axialy loaded back-to-back cold-formed steel built-up channel sections. Advances in Structural Engineering. 2018; 21(3):474-487.

[41] Roy K, Ting TCH, Lau HH, Lim JBP. Nonlinear behavior of axially loaded back-toback built-up cold-formed steel un-lipped channel sections. Steel and Composite Structures, An International Journal. 2018; 28(2):233-250.

[42] Roy K, Ting TCH, Lau HH, Lim JBP. Nonlinear behaviour of back-to-back gapped built-up cold-formed steel channel sections under compression. Journal of Constructional Steel Research. 2018; 147:257-276.

[43] Roy K, Mohammadjani C, Lim JBP. Experimental and numerical investigation into the behaviour of face-to-face built-up cold-formed steel channel sections under compression. Thin-Walled Structures. 2019. 134; 291-309.

[44] Yousefi, A. M., Lim, J. B., Uzzaman, A., Lian, Y., Clifton, G. C., \& Young, B. Design of cold-formed stainless steel lipped channel sections with web openings subjected to web crippling under end-one-flange loading condition. Advances in Structural Engineering. 2017; 20(7); 1024-1045.

[45] Yousefi, A. M., Uzzaman, A., Lim, J. B. P., Clifton, G. C., \& Young, B. . Numerical investigation of web crippling strength in cold-formed stainless steel lipped channels with web openings subjected to interior-two-flange loading condition. Steel and Composite Structures. 2017; 23(3); 363-383.

[46] Yousefi, A.M., Lim, J.B.P., Uzzaman, A., Lian, Y., Clifton, G.C., Young, B. Web crippling strength of cold-formed duplex stainless steel lipped channel-sections with web openings subjected to interior-one-flange loading condition. Wei-Wen Yu International Specialty Conference on Cold-Formed Steel Structures; 2016; pp. 313-324 
[47] NAS. North American Specification for the design of cold-formed steel structural members. Washington, D.C.: American Iron and Steel Institute; 2016.

[48] ASCE. Minimum design loads for buildings and other structures. New York: American Society of Civil Engineers Standard; 2005. 
Table 1 Measured specimen dimensions and experimental ultimate loads for offset web holes

\begin{tabular}{|c|c|c|c|c|c|c|c|c|c|c|}
\hline Specimen & $\begin{array}{c}\text { Web } \\
d \\
(\mathrm{~mm})\end{array}$ & $\begin{array}{c}b_{f} \\
(\mathrm{~mm})\end{array}$ & $\begin{array}{c}\text { Lip } \\
b_{l} \\
(\mathrm{~mm})\end{array}$ & $\begin{array}{c}L \\
(\mathrm{~mm})\end{array}$ & $\begin{array}{c}t \\
(\mathrm{~mm})\end{array}$ & $\begin{array}{c}r_{i} \\
(\mathrm{~mm})\end{array}$ & Hole diameter & Bearing length & $\begin{array}{c}\text { Exp.load } \\
\text { (Per web ) } \\
P_{E X P} \\
(\mathrm{kN})\end{array}$ & $\begin{array}{l}\text { Percentage of strength } \\
\text { reduction due to web holes } \\
R \\
(\%)\end{array}$ \\
\hline \multicolumn{11}{|l|}{ Plain section } \\
\hline ETF 240x45x15-N50-NH & 237 & 44.95 & 18.29 & 768.33 & 1.98 & 3.0 & - & 50 & 3.32 & - \\
\hline ETF $240 \times 45 \times 15-\mathrm{N} 75-\mathrm{NH}$ & 237.67 & 45.04 & 18.27 & 794 & 1.97 & 3.0 & - & 75 & 3.71 & - \\
\hline ETF $240 \times 45 \times 15-\mathrm{N} 100-\mathrm{NH}$ & 237.33 & 45.06 & 17.75 & 820 & 1.96 & 3.0 & - & 100 & 4.11 & - \\
\hline ETF 290x45x15-N50-NH & 290.33 & 45.51 & 18.01 & 919.67 & 2.46 & 3.0 & - & 50 & 7.13 & - \\
\hline ETF 290x45x15-N75-NH & 289.33 & 45.37 & 18.55 & 944 & 2.47 & 3.0 & - & 75 & 7.44 & - \\
\hline ETF $290 \times 45 \times 15-\mathrm{N} 100-\mathrm{NH}$ & 290.67 & 45.35 & 18.47 & 969.67 & 2.47 & 3.0 & - & 100 & 8.11 & - \\
\hline \multicolumn{11}{|l|}{ Unstiffened offset hole } \\
\hline ETF 240x45x15-N50-USOH & 236 & 45.1 & 17.56 & 770 & 1.96 & 3.0 & 140 & 50 & 2.34 & -29.5 \\
\hline ETF 240x45x15-N75-USOH & 236 & 44.72 & 17.68 & 795 & 1.96 & 3.0 & 140 & 75 & 2.5 & -32.6 \\
\hline ETF 240x45x15-N100-USOH & 236 & 44.67 & 17.65 & 820 & 1.96 & 3.0 & 140 & 100 & 2.73 & -33.6 \\
\hline ETF 290x45x15-N50-USOH & 290 & 45.31 & 18.22 & 920 & 2.48 & 3.0 & 140 & 50 & 5.74 & -19.5 \\
\hline ETF 290x45x15-N75-USOH & 289 & 45.27 & 18.24 & 944 & 2.48 & 3.0 & 140 & 75 & 6.05 & -18.7 \\
\hline ETF 290x45x15-N100-USOH & 290 & 44.6 & 19.57 & 970 & 2.48 & 3.0 & 140 & 100 & 6.35 & -21.7 \\
\hline \multicolumn{11}{|l|}{ Edge-stiffened offset hole } \\
\hline ETF 240x45x15-N50-ESOH & 237.67 & 45.09 & 17.6 & 770 & 1.97 & 3.0 & 140 & 50 & 3.88 & 16.9 \\
\hline ETF 240x45x15-N75-ESOH & 237.33 & 44.75 & 17.66 & 795 & 1.96 & 3.0 & 140 & 75 & 3.96 & 6.7 \\
\hline ETF 240x45x15-N100-ESOH & 237 & 44.69 & 17.58 & 820 & 1.96 & 3.0 & 140 & 100 & 4.4 & 7.1 \\
\hline ETF 290x45x15-N50-ESOH & 289.67 & 45.35 & 18.13 & 920 & 2.48 & 3.0 & 140 & 50 & 7.86 & 10.2 \\
\hline ETF 290x45x15-N75-ESOH & 289.33 & 45.28 & 18.17 & 944 & 2.48 & 3.0 & 140 & 75 & 8 & 7.5 \\
\hline ETF 290x45x15-N100-ESOH & 289.67 & 44.65 & 19.55 & 970 & 2.48 & 3.0 & 140 & 100 & 8.6 & 6.0 \\
\hline
\end{tabular}


Table 2 Measured specimen dimensions and experimental ultimate loads for down web hole

\begin{tabular}{|c|c|c|c|c|c|c|c|c|c|c|}
\hline Specimen & $\begin{array}{l}\text { Web } \\
d \\
(\mathrm{~mm})\end{array}$ & $\begin{array}{c}b_{f} \\
(\mathrm{~mm})\end{array}$ & $\begin{array}{c}b_{l} \\
(\mathrm{~mm})\end{array}$ & $\begin{array}{c}L \\
(\mathrm{~mm})\end{array}$ & $\begin{array}{c}t \\
(\mathrm{~mm})\end{array}$ & $\begin{array}{c}r_{i} \\
(\mathrm{~mm})\end{array}$ & $\begin{array}{c}a \\
(\mathrm{~mm})\end{array}$ & Bearing length & $\begin{array}{c}\text { Exp.load } \\
\text { (Per web ) } \\
P_{E X P} \\
(\mathrm{kN})\end{array}$ & $\begin{array}{l}\text { Percentage of strength reduction } \\
\text { due to web holes } \\
\qquad R \\
(\%)\end{array}$ \\
\hline \multicolumn{11}{|l|}{ Plain section } \\
\hline ETF 240x45x15-N50-NH & 237 & 44.95 & 18.29 & 768.33 & 1.98 & 3.0 & - & 50 & 3.32 & - \\
\hline ETF 240x45x15-N75-NH & 237.67 & 45.04 & 18.27 & 794 & 1.97 & 3.0 & - & 75 & 3.71 & - \\
\hline ETF 240x45x15-N100-NH & 237.33 & 45.06 & 17.75 & 820 & 1.96 & 3.0 & - & 100 & 4.11 & - \\
\hline ETF 290x45x15-N50-NH & 290.33 & 45.51 & 18.01 & 919.67 & 2.46 & 3.0 & - & 50 & 7.13 & - \\
\hline ETF 290x45x15-N75-NH & 289.33 & 45.37 & 18.55 & 944 & 2.47 & 3.0 & - & 75 & 7.44 & - \\
\hline ETF 290x45x15-N100-NH & 290.67 & 45.35 & 18.47 & 969.67 & 2.47 & 3.0 & - & 100 & 8.11 & - \\
\hline \multicolumn{11}{|l|}{ Unstiffened down hole } \\
\hline ETF 240x45x15-N50-USCH & 236.00 & 44.84 & 17.66 & 770 & 1.98 & 3.0 & 140 & 50 & 1.66 & -50.0 \\
\hline ETF 240x45x15-N75-USCH & 236.00 & 45.57 & 17.64 & 795 & 1.96 & 3.0 & 140 & 75 & 1.9 & -48.8 \\
\hline ETF $240 \times 45 \times 15-N 100-U S C H$ & 236.00 & 45.16 & 17.7 & 819 & 1.96 & 3.0 & 140 & 100 & 2.14 & -47.9 \\
\hline ETF 290x45x15-N50-USCH & 289.00 & 44.59 & 20.33 & 919 & 2.48 & 3.0 & 140 & 50 & 3.8 & -46.7 \\
\hline ETF 290x45x15-N75-USCH & 289.00 & 44.62 & 20.24 & 944 & 2.47 & 3.0 & 140 & 75 & 4.43 & -40.5 \\
\hline ETF 290x45x15-N100-USCH & 289.00 & 44.6 & 20.23 & 970 & 2.47 & 3.0 & 140 & 100 & 4.48 & -44.8 \\
\hline \multicolumn{11}{|l|}{ Edge-stiffened down hole } \\
\hline ETF 240x45x15-N50-ESCH & 237.33 & 44.8 & 17.63 & 770 & 1.98 & 3.0 & 140 & 50 & 4.58 & 37.9 \\
\hline ETF 240x45x15-N75-ESCH & 237.33 & 45.29 & 17.69 & 795 & 1.97 & 3.0 & 140 & 75 & 5.09 & 37.2 \\
\hline ETF $240 \times 45 \times 15-N 100-E S C H$ & 237.00 & 45.11 & 17.77 & 819 & 1.96 & 3.0 & 140 & 100 & 5.3 & 28.9 \\
\hline ETF 290x45x15-N50-ESCH & 290.00 & 44.65 & 20.34 & 919 & 2.47 & 3.0 & 140 & 50 & 8.67 & 21.6 \\
\hline ETF 290x45x15-N75-ESCH & 290.00 & 44.72 & 20.25 & 944 & 2.47 & 3.0 & 140 & 75 & 8.69 & 16.8 \\
\hline ETF $290 \times 45 \times 15-N 100-E S C H$ & 290.00 & 44.61 & 20.26 & 970 & 2.48 & 3.0 & 140 & 100 & 8.71 & 7.4 \\
\hline
\end{tabular}


Table 3 Average material properties of specimens

\begin{tabular}{llll}
\hline & Section & $\begin{array}{l}\sigma_{\mathrm{o} .2} \\
(\mathrm{MPa})\end{array}$ & $\sigma_{u}(\mathrm{MPa})$ \\
\hline \multirow{2}{*}{$240 \times 45 \times 15-\mathrm{t} 1.85$} & 1 & 264.8 & 284.8 \\
& 2 & 268.8 & 283.7 \\
& 3 & 263.4 & 287.8 \\
\hline \multirow{2}{*}{$290 \times 45 \times 15-\mathrm{t} 2.5$} & 1 & 318.9 & 410.2 \\
& 2 & 328.6 & 413.3 \\
& 3 & 332.8 & 414.5 \\
\hline
\end{tabular}


Table 4 Comparison of the web crippling strength predicted from the finite element analysis with the experiment results for offset web holes

\begin{tabular}{|c|c|c|c|c|c|}
\hline Specimen & $\begin{array}{l}\text { Web slenderness, } \\
(h / t)\end{array}$ & $\begin{array}{l}\text { Web hole ratio, } \\
(a / h)\end{array}$ & $\begin{array}{l}\text { Exp. load per web, } \\
P_{\text {EXP }(\mathrm{kN})}\end{array}$ & $\begin{array}{l}\text { Web crippling strength per web } \\
\text { predicted from FEA, } P_{\text {FEA }}(\mathrm{kN})\end{array}$ & $\begin{array}{l}\text { Comparison, } \\
P_{\mathrm{EXP}} / P_{\mathrm{FEA}}\end{array}$ \\
\hline \multicolumn{6}{|l|}{ Plain section } \\
\hline ETF 240x45x15-N50-NH & 117.7 & 0 & 3.32 & 3.44 & 0.97 \\
\hline ETF 240x45x15-N75-NH & 117.9 & 0 & 3.71 & 3.90 & 0.95 \\
\hline ETF 240x45x15-N100-NH & 118.2 & 0 & 4.11 & 4.37 & 0.94 \\
\hline ETF 290x45x15-N50-NH & 115.2 & 0 & 7.13 & 6.86 & 1.04 \\
\hline ETF 290x45x15-N75-NH & 115.2 & 0 & 7.44 & 7.59 & 0.98 \\
\hline ETF 290x45x15-N100-NH & 115.7 & 0 & 8.11 & 7.60 & 1.07 \\
\hline \multicolumn{6}{|l|}{ Unstiffened offset hole } \\
\hline ETF 240x45x15-N50-USOH & 118.2 & 0.6 & 2.34 & 2.30 & 1.02 \\
\hline ETF 240x45x15-N75-USOH & 117.7 & 0.6 & 2.5 & 2.60 & 0.96 \\
\hline ETF 240x45x15-N100-USOH & 117.7 & 0.6 & 2.73 & 3.00 & 0.91 \\
\hline ETF 290x45x15-N50-USOH & 115.4 & 0.5 & 5.74 & 5.77 & 0.99 \\
\hline ETF 290x45x15-N75-USOH & 114.5 & 0.5 & 6.05 & 6.02 & 1.00 \\
\hline ETF 290x45x15-N100-USOH & 115.9 & 0.5 & 6.35 & 6.53 & 0.97 \\
\hline \multicolumn{6}{|l|}{ Edge-stiffened offset hole } \\
\hline ETF 240x45x15-N50-ESOH & 119.0 & 0.6 & 3.88 & 3.86 & 1.01 \\
\hline ETF 240x45x15-N75-ESOH & 117.9 & 0.6 & 3.96 & 4.10 & 0.97 \\
\hline ETF 240x45x15-N100-ESOH & 118.2 & 0.6 & 4.4 & 4.29 & 1.03 \\
\hline ETF 290x45x15-N50-ESOH & 114.9 & 0.5 & 7.86 & 7.88 & 1.00 \\
\hline ETF 290x45x15-N75-ESOH & 114.7 & 0.5 & 8 & 7.75 & 1.03 \\
\hline ETF 290x45x15-N100-ESOH & 114.8 & 0.5 & 8.6 & 8.04 & 1.07 \\
\hline Mean & & & & & 0.99 \\
\hline $\mathrm{COV}$ & & & & & 0.04 \\
\hline
\end{tabular}


Table 5 Comparison of the web crippling strength predicted from the finite element analysis with the experiment results for down web hole

\begin{tabular}{|c|c|c|c|c|c|}
\hline Specimen & $\begin{array}{l}\text { Web slenderness, } \\
(h / t)\end{array}$ & $\begin{array}{l}\text { Web hole ratio, } \\
(a / h)\end{array}$ & $\begin{array}{l}\text { Exp. load per web, } \\
P_{\text {EXP }}(\mathrm{kN})\end{array}$ & $\begin{array}{l}\text { Web crippling strength per web } \\
\text { predicted from FEA, } P_{\text {FEA }}(\mathrm{kN})\end{array}$ & $\begin{array}{l}\text { Comparison, } \\
P_{\mathrm{EXP}} / P_{\mathrm{FEA}}\end{array}$ \\
\hline \multicolumn{6}{|l|}{ Plain section } \\
\hline ETF 240x45x15-N50-NH & 117.7 & 0 & 3.32 & 3.44 & 0.97 \\
\hline ETF $240 \times 45 \times 15-N 75-N H$ & 118.6 & 0 & 3.71 & 3.90 & 0.95 \\
\hline ETF $240 \times 45 \times 15-\mathrm{N} 100-\mathrm{NH}$ & 119.1 & 0 & 4.11 & 4.37 & 0.94 \\
\hline ETF 290x45x15-N50-NH & 116.0 & 0 & 7.13 & 6.86 & 1.04 \\
\hline ETF 290x45x15-N75-NH & 115.1 & 0 & 7.44 & 7.10 & 1.05 \\
\hline ETF $290 \times 45 \times 15-N 100-N H$ & 115.7 & 0 & 8.11 & 7.60 & 1.07 \\
\hline \multicolumn{6}{|l|}{ Unstiffened down hole } \\
\hline ETF 240x45x15-N50-USCH & 117.2 & 0.6 & 1.66 & 1.70 & 0.98 \\
\hline ETF 240x45x15-N75-USCH & 118.4 & 0.6 & 1.9 & 1.95 & 0.97 \\
\hline ETF $240 \times 45 \times 15-N 100-U S C H$ & 118.4 & 0.6 & 2.14 & 2.29 & 0.93 \\
\hline ETF 290x45x15-N50-USCH & 114.5 & 0.5 & 3.8 & 4.05 & 0.94 \\
\hline ETF 290x45x15-N75-USCH & 115.0 & 0.5 & 4.43 & 4.51 & 0.98 \\
\hline ETF 290x45x15-N100-USCH & 115.0 & 0.5 & 4.48 & 4.63 & 0.97 \\
\hline \multicolumn{6}{|l|}{ Edge-stiffened down hole } \\
\hline ETF 240x45x15-N50-ESCH & 117.9 & 0.6 & 4.58 & 4.43 & 1.03 \\
\hline ETF 240x45x15-N75-ESCH & 118.5 & 0.6 & 5.09 & 4.95 & 1.03 \\
\hline ETF 240x45x15-N100-ESCH & 118.9 & 0.6 & 5.3 & 5.40 & 0.98 \\
\hline ETF 290x45x15-N50-ESCH & 115.4 & 0.5 & 8.67 & 7.96 & 1.09 \\
\hline ETF 290x45x15-N75-ESCH & 115.4 & 0.5 & 8.69 & 8.49 & 1.02 \\
\hline ETF 290x45x15-N100-ESCH & 114.9 & 0.5 & 8.71 & 8.70 & 1.00 \\
\hline Mean & & & & & 1.00 \\
\hline $\mathrm{COV}$ & & & & & 0.05 \\
\hline
\end{tabular}


Table 6 Dimensions and web crippling strengths predicted from FEA of a parametric study for 2.0 mm thickness under offset web holes

\begin{tabular}{|c|c|c|c|c|c|c|c|c|c|c|c|c|c|c|c|c|}
\hline \multirow{3}{*}{$\begin{array}{l}\text { Thickness } \\
t \\
(\mathrm{~mm})\end{array}$} & \multirow{3}{*}{$\begin{array}{l}\text { Bearing } \\
\text { length } \\
N \\
(\mathrm{~mm})\end{array}$} & \multirow{3}{*}{$\begin{array}{l}\text { Holes } \\
\text { diameter } \\
\text { ratio, } \\
A(a / h)\end{array}$} & \multirow{3}{*}{$\begin{array}{l}\text { Holes } \\
\text { diameter } \\
a \\
(\mathrm{~mm})\end{array}$} & \multirow{3}{*}{$\begin{array}{l}\text { Holes } \\
\text { distance } \\
\text { ratio, } \\
X(x / h)\end{array}$} & \multirow{3}{*}{$\begin{array}{l}\text { Holes } \\
\text { distance } \\
(x) \\
(\mathrm{mm})\end{array}$} & \multicolumn{11}{|c|}{ Web crippling strength per web predicted from FEA, $P_{\mathrm{FEA}}(\mathrm{kN})$} \\
\hline & & & & & & \multirow{2}{*}{$\begin{array}{l}\text { Without } \\
\text { hole }\end{array}$} & \multirow{2}{*}{$\begin{array}{l}\text { With } \\
\text { Circular } \\
\text { Holes }\end{array}$} & \multicolumn{9}{|c|}{ With Edge Stiffened holes } \\
\hline & & & & & & & & \multicolumn{3}{|c|}{ Stiffened radius $\left(\mathrm{r}_{\mathrm{q}}\right)=2(\mathrm{~mm})$} & \multicolumn{3}{|c|}{ Stiffened radius $\left(r_{\mathrm{q}}\right)=4(\mathrm{~mm})$} & \multicolumn{3}{|c|}{ Stiffened radius $\left(\mathrm{r}_{\mathrm{q}}\right)=6(\mathrm{~mm})$} \\
\hline & & & & & & & & Q0.04 & Q0.06 & Q0.08 & Q0.04 & Q0.06 & Q0.08 & Q0.04 & Q0.06 & Q0.08 \\
\hline 2.0 & 50.00 & 0.40 & 94.40 & 0.20 & 47.20 & 3.70 & 2.78 & 4.06 & 4.09 & 4.11 & 4.08 & 4.11 & 4.13 & 4.10 & 4.13 & 4.14 \\
\hline 2.0 & 50.00 & 0.60 & 141.60 & 0.20 & 47.20 & 3.70 & 2.36 & 4.13 & 4.30 & 4.35 & 4.13 & 4.30 & 4.35 & 4.13 & 4.30 & 4.35 \\
\hline 2.0 & 50.00 & 0.80 & 188.80 & 0.20 & 47.20 & 3.70 & 2.04 & 3.55 & 4.12 & 4.24 & 3.55 & 4.11 & 4.23 & 3.57 & 4.11 & 4.23 \\
\hline 2.0 & 75.00 & 0.40 & 94.40 & 0.20 & 47.20 & 4.08 & 3.20 & 4.48 & 4.52 & 4.54 & 4.50 & 4.54 & 4.56 & 4.53 & 4.56 & 4.58 \\
\hline 2.0 & 75.00 & 0.60 & 141.60 & 0.20 & 47.20 & 4.08 & 2.81 & 4.54 & 4.73 & 4.79 & 4.55 & 4.73 & 4.79 & 4.56 & 4.74 & 4.80 \\
\hline 2.0 & 75.00 & 0.80 & 188.80 & 0.20 & 47.20 & 4.08 & 2.51 & 4.03 & 4.58 & 4.72 & 4.04 & 4.60 & 4.71 & 4.06 & 4.60 & 4.72 \\
\hline 2.0 & 100.00 & 0.40 & 94.40 & 0.20 & 47.20 & 4.50 & 3.66 & 4.91 & 4.97 & 4.99 & 4.94 & 4.99 & 5.01 & 4.97 & 5.01 & 5.04 \\
\hline 2.0 & 100.00 & 0.60 & 141.60 & 0.20 & 47.20 & 4.50 & 3.29 & 4.99 & 5.19 & 5.26 & 5.00 & 5.20 & 5.27 & 5.03 & 5.21 & 5.28 \\
\hline 2.0 & 50.00 & 0.40 & 94.40 & 0.40 & 94.40 & 3.70 & 3.02 & 4.04 & 4.09 & 4.11 & 4.06 & 4.10 & 4.12 & 4.08 & 4.11 & 4.13 \\
\hline 2.0 & 50.00 & 0.60 & 141.60 & 0.40 & 94.40 & 3.70 & 2.70 & 4.00 & 4.12 & 4.18 & 4.01 & 4.12 & 4.18 & 4.01 & 4.12 & 4.17 \\
\hline 2.0 & 50.00 & 0.80 & 188.80 & 0.40 & 94.40 & 3.70 & 2.47 & 3.64 & 3.95 & 4.04 & 3.64 & 3.95 & 4.03 & 3.64 & 3.93 & 4.02 \\
\hline 2.0 & 75.00 & 0.40 & 94.40 & 0.40 & 94.40 & 4.08 & 3.45 & 4.42 & 4.47 & 4.50 & 4.44 & 4.49 & 4.52 & 4.46 & 4.51 & 4.53 \\
\hline 2.0 & 75.00 & 0.60 & 141.60 & 0.40 & 94.40 & 4.08 & 3.14 & 4.40 & 4.52 & 4.58 & 4.41 & 4.52 & 4.58 & 4.42 & 4.53 & 4.58 \\
\hline 2.0 & 75.00 & 0.80 & 188.80 & 0.40 & 94.40 & 4.08 & 2.91 & 4.09 & 4.38 & 4.47 & 4.09 & 4.37 & 4.46 & 4.10 & 4.36 & 4.45 \\
\hline 2.0 & 100.00 & 0.40 & 94.40 & 0.40 & 94.40 & 4.50 & 3.90 & 4.82 & 4.87 & 4.91 & 4.84 & 4.89 & 4.92 & 4.86 & 4.91 & 4.94 \\
\hline 2.0 & 100.00 & 0.60 & 141.60 & 0.40 & 94.40 & 4.50 & 3.60 & 4.82 & 4.94 & 5.00 & 4.83 & 4.94 & 5.01 & 4.85 & 4.95 & 5.01 \\
\hline 2.0 & 100.00 & 0.80 & 188.80 & 0.40 & 94.40 & 4.50 & 3.37 & 4.57 & 4.82 & 4.92 & 4.58 & 4.82 & 4.91 & 4.58 & 4.81 & 4.90 \\
\hline 2.0 & 50.00 & 0.40 & 94.40 & 0.60 & 141.60 & 3.70 & 3.23 & 3.95 & 3.99 & 4.02 & 3.96 & 4.00 & 4.02 & 3.97 & 4.01 & 4.03 \\
\hline 2.0 & 50.00 & 0.60 & 141.60 & 0.60 & 141.60 & 3.70 & 3.02 & 3.89 & 3.97 & 4.02 & 3.90 & 3.97 & 4.02 & 3.90 & 3.97 & 4.02 \\
\hline 2.0 & 50.00 & 0.80 & 188.80 & 0.60 & 141.60 & 3.70 & 2.84 & 3.64 & 3.78 & 3.85 & 3.63 & 3.77 & 3.84 & 3.60 & 3.74 & 3.81 \\
\hline 2.0 & 75.00 & 0.40 & 94.40 & 0.60 & 141.60 & 4.08 & 3.65 & 4.30 & 4.34 & 4.37 & 4.32 & 4.35 & 4.38 & 4.33 & 4.36 & 4.39 \\
\hline 2.0 & 100.00 & 0.40 & 94.40 & 0.60 & 141.60 & 4.50 & 4.09 & 4.69 & 4.73 & 4.76 & 4.70 & 4.74 & 4.77 & 4.71 & 4.75 & 4.77 \\
\hline 2.0 & 100.00 & 0.60 & 141.60 & 0.60 & 141.60 & 4.50 & 3.87 & 4.66 & 4.72 & 4.77 & 4.66 & 4.73 & 4.77 & 4.67 & 4.73 & 4.77 \\
\hline 2.0 & 100.00 & 0.80 & 188.80 & 0.60 & 141.60 & 4.50 & 3.69 & 4.47 & 4.57 & 4.63 & 4.47 & 4.56 & 4.62 & 4.45 & 4.54 & 4.61 \\
\hline
\end{tabular}


Table 7 Dimensions and web crippling strengths predicted from FEA of a parametric study for 4.0 mm thickness under offset web holes

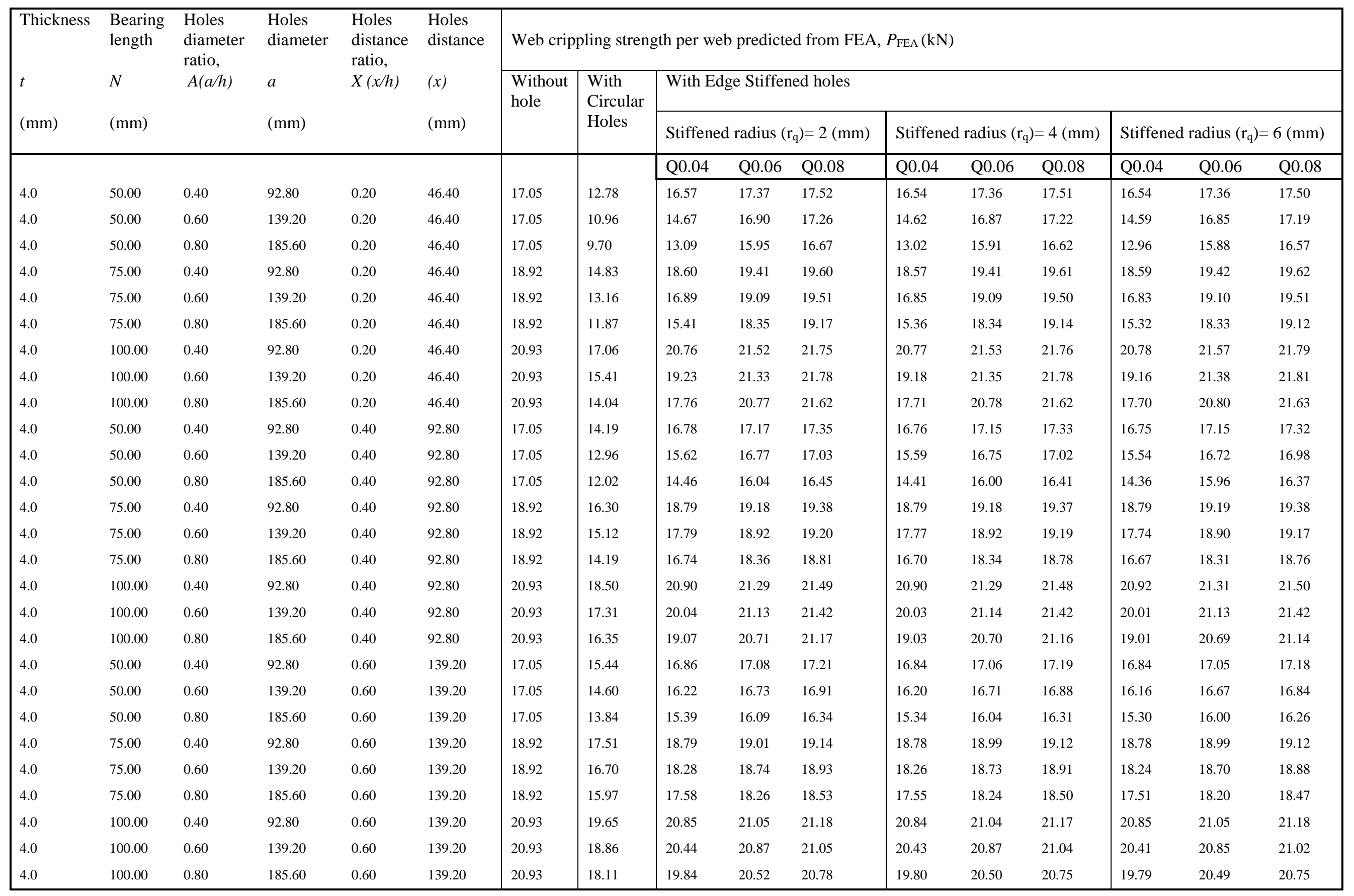


Table 8 Dimensions and web crippling strengths predicted from FEA of a parametric study for $6.0 \mathrm{~mm}$ thickness under offset web holes

\begin{tabular}{|c|c|c|c|c|c|c|c|c|c|c|c|c|c|c|c|c|}
\hline \multirow{3}{*}{$\begin{array}{l}\text { Thickness } \\
t \\
(\mathrm{~mm})\end{array}$} & \multirow{3}{*}{$\begin{array}{l}\text { Bearing } \\
\text { length } \\
N \\
(\mathrm{~mm})\end{array}$} & \multirow{3}{*}{$\begin{array}{l}\text { Holes } \\
\text { diameter } \\
\text { ratio, } \\
A(a / h)\end{array}$} & \multirow{3}{*}{$\begin{array}{l}\text { Holes } \\
\text { diameter } \\
a \\
(\mathrm{~mm})\end{array}$} & \multirow{3}{*}{$\begin{array}{l}\text { Holes } \\
\text { distance } \\
\text { ratio, } \\
X(x / h)\end{array}$} & \multirow{3}{*}{$\begin{array}{l}\text { Holes } \\
\text { distance } \\
(x) \\
(\mathrm{mm})\end{array}$} & \multicolumn{11}{|c|}{ Web crippling strength per web predicted from FEA, $P_{\mathrm{FEA}}(\mathrm{kN})$} \\
\hline & & & & & & \multirow{2}{*}{$\begin{array}{l}\text { Without } \\
\text { hole }\end{array}$} & \multirow{2}{*}{$\begin{array}{l}\text { With } \\
\text { Circular } \\
\text { Holes }\end{array}$} & \multicolumn{9}{|c|}{ With Edge Stiffened holes } \\
\hline & & & & & & & & \multicolumn{3}{|c|}{ Stiffened radius $\left(\mathrm{r}_{\mathrm{q}}\right)=2(\mathrm{~mm})$} & \multicolumn{3}{|c|}{ Stiffened radius $\left(r_{\mathrm{q}}\right)=4(\mathrm{~mm})$} & \multicolumn{3}{|c|}{ Stiffened radius $\left(\mathrm{r}_{\mathrm{q}}\right)=6(\mathrm{~mm})$} \\
\hline & & & & & & & & Q0.04 & Q0.06 & Q0.08 & Q0.04 & Q0.06 & Q0.08 & Q0.04 & Q0.06 & Q0.08 \\
\hline 6.0 & 50.00 & 0.40 & 91.20 & 0.20 & 45.60 & 36.53 & 29.84 & 34.91 & 36.30 & 36.73 & 34.82 & 36.27 & 36.70 & 34.75 & 36.25 & 36.68 \\
\hline 6.0 & 50.00 & 0.60 & 136.80 & 0.20 & 45.60 & 36.53 & 25.71 & 31.11 & 35.26 & 36.06 & 30.96 & 35.21 & 36.02 & 30.84 & 35.17 & 35.98 \\
\hline 6.0 & 50.00 & 0.80 & 182.40 & 0.20 & 45.60 & 36.53 & 22.66 & 27.69 & 32.85 & 35.14 & 27.53 & 32.74 & 35.07 & 27.36 & 32.61 & 34.99 \\
\hline 6.0 & 75.00 & 0.40 & 91.20 & 0.20 & 45.60 & 42.16 & 34.51 & 39.95 & 42.17 & 42.66 & 39.86 & 42.16 & 42.65 & 39.79 & 42.16 & 42.65 \\
\hline 6.0 & 75.00 & 0.60 & 136.80 & 0.20 & 45.60 & 42.16 & 30.54 & 36.09 & 40.82 & 42.14 & 35.94 & 40.78 & 42.11 & 35.82 & 40.75 & 42.09 \\
\hline 6.0 & 75.00 & 0.80 & 182.40 & 0.20 & 45.60 & 42.16 & 27.50 & 32.76 & 38.16 & 41.25 & 32.62 & 38.06 & 41.20 & 32.47 & 37.96 & 41.16 \\
\hline 6.0 & 100.00 & 0.40 & 91.20 & 0.20 & 45.60 & 47.13 & 39.32 & 44.86 & 47.35 & 47.92 & 44.78 & 47.35 & 47.92 & 44.72 & 47.37 & 47.94 \\
\hline 6.0 & 100.00 & 0.60 & 136.80 & 0.20 & 45.60 & 47.13 & 35.44 & 41.11 & 46.01 & 47.53 & 40.98 & 45.94 & 47.52 & 40.88 & 45.92 & 47.53 \\
\hline 6.0 & 50.00 & 0.40 & 91.20 & 0.40 & 91.20 & 36.53 & 32.96 & 35.79 & 36.32 & 36.60 & 35.74 & 36.30 & 36.58 & 35.70 & 36.28 & 36.56 \\
\hline 6.0 & 50.00 & 0.60 & 136.80 & 0.40 & 91.20 & 36.53 & 30.27 & 33.92 & 35.67 & 36.10 & 33.84 & 35.65 & 36.08 & 33.72 & 35.59 & 36.03 \\
\hline 6.0 & 50.00 & 0.80 & 182.40 & 0.40 & 91.20 & 36.53 & 28.00 & 31.56 & 34.40 & 35.34 & 31.46 & 34.33 & 35.29 & 31.31 & 34.22 & 35.22 \\
\hline 6.0 & 75.00 & 0.40 & 91.20 & 0.40 & 91.20 & 42.16 & 37.82 & 41.19 & 42.07 & 42.42 & 41.14 & 42.06 & 42.41 & 41.10 & 42.04 & 42.39 \\
\hline 6.0 & 75.00 & 0.60 & 136.80 & 0.40 & 91.20 & 42.16 & 35.08 & 39.00 & 41.35 & 41.97 & 38.93 & 41.34 & 41.96 & 38.79 & 41.29 & 41.92 \\
\hline 6.0 & 75.00 & 0.80 & 182.40 & 0.40 & 91.20 & 42.16 & 32.84 & 36.63 & 39.92 & 41.26 & 36.55 & 39.86 & 41.23 & 36.41 & 39.76 & 41.16 \\
\hline 6.0 & 100.00 & 0.40 & 91.20 & 0.40 & 91.20 & 47.13 & 42.67 & 46.18 & 47.19 & 47.58 & 46.15 & 47.20 & 47.59 & 46.13 & 47.21 & 47.59 \\
\hline 6.0 & 100.00 & 0.60 & 136.80 & 0.40 & 91.20 & 47.13 & 39.97 & 43.98 & 46.54 & 47.26 & 43.92 & 46.54 & 47.26 & 43.83 & 46.50 & 47.23 \\
\hline 6.0 & 100.00 & 0.80 & 182.40 & 0.40 & 91.20 & 47.13 & 37.73 & 41.70 & 45.17 & 46.69 & 41.63 & 45.13 & 46.67 & 41.51 & 45.04 & 46.62 \\
\hline 6.0 & 50.00 & 0.40 & 91.20 & 0.60 & 136.80 & 36.53 & 35.11 & 36.11 & 36.34 & 36.49 & 36.09 & 36.32 & 36.47 & 36.06 & 36.30 & 36.45 \\
\hline 6.0 & 50.00 & 0.60 & 136.80 & 0.60 & 136.80 & 36.53 & 33.64 & 35.33 & 35.90 & 36.14 & 35.29 & 35.87 & 36.11 & 35.22 & 35.83 & 36.06 \\
\hline 6.0 & 50.00 & 0.80 & 182.40 & 0.60 & 136.80 & 36.53 & 32.01 & 34.02 & 35.16 & 35.58 & 33.95 & 35.11 & 35.53 & 33.84 & 35.04 & 35.47 \\
\hline 6.0 & 75.00 & 0.40 & 91.20 & 0.60 & 136.80 & 42.16 & 40.20 & 41.67 & 42.02 & 42.23 & 41.65 & 42.01 & 42.22 & 41.63 & 41.99 & 42.19 \\
\hline 6.0 & 100.00 & 0.40 & 91.20 & 0.60 & 136.80 & 47.13 & 45.06 & 46.65 & 47.08 & 47.31 & 46.65 & 47.08 & 47.31 & 46.63 & 47.08 & 47.30 \\
\hline 6.0 & 100.00 & 0.60 & 136.80 & 0.60 & 136.80 & 47.13 & 43.41 & 45.65 & 46.66 & 47.05 & 45.62 & 46.66 & 47.05 & 45.55 & 46.61 & 47.01 \\
\hline 6.0 & 100.00 & 0.80 & 182.40 & 0.60 & 136.80 & 47.13 & 41.78 & 44.28 & 45.94 & 46.60 & 44.23 & 45.91 & 46.58 & 44.13 & 45.84 & 46.53 \\
\hline
\end{tabular}


Table 9 Dimensions and web crippling strengths predicted from FEA of a parametric study for down web hole

\begin{tabular}{|c|c|c|c|c|c|c|c|c|c|c|c|c|c|c|c|}
\hline \multirow{3}{*}{$\begin{array}{l}\text { Thickness } \\
t \\
(\mathrm{~mm})\end{array}$} & \multirow{3}{*}{$\begin{array}{l}\text { Bearing } \\
\text { length } \\
N \\
(\mathrm{~mm})\end{array}$} & \multirow{3}{*}{$\begin{array}{l}\text { Bearing } \\
\text { length } \\
\text { ratio, } \\
(N / h)\end{array}$} & \multirow{3}{*}{$\begin{array}{l}\text { Holes } \\
\text { diameter } \\
\text { ratio, } \\
A(a / h)\end{array}$} & \multirow{3}{*}{$\begin{array}{l}\text { Holes } \\
\text { diameter } \\
a \\
(\mathrm{~mm})\end{array}$} & \multicolumn{11}{|c|}{ Web crippling strength per web predicted from FEA, $P_{\mathrm{FEA}}(\mathrm{kN})$} \\
\hline & & & & & \multirow{2}{*}{$\begin{array}{l}\text { Without } \\
\text { hole }\end{array}$} & \multirow{2}{*}{$\begin{array}{l}\text { With } \\
\text { Circular } \\
\text { Holes }\end{array}$} & \multicolumn{9}{|c|}{ With Edge Stiffened holes } \\
\hline & & & & & & & \multicolumn{3}{|c|}{ Stiffened radius $\left(r_{q}\right)=2(\mathrm{~mm})$} & \multicolumn{3}{|c|}{ Stiffened radius $\left(r_{q}\right)=4(\mathrm{~mm})$} & \multicolumn{3}{|c|}{ Stiffened radius $\left(\mathrm{r}_{\mathrm{q}}\right)=6(\mathrm{~mm})$} \\
\hline & & & & & & & Q0.04 & Q0.06 & Q0.08 & Q0.04 & Q0.06 & Q0.08 & Q0.04 & Q0.06 & Q0.08 \\
\hline 2.0 & 50.00 & 0.21 & 0.40 & 94.40 & 3.70 & 2.54 & 3.59 & 3.64 & 3.73 & 4.33 & 4.45 & 4.54 & 4.87 & 4.98 & 5.12 \\
\hline 2.0 & 50.00 & 0.21 & 0.60 & 141.60 & 3.70 & 2.02 & 3.61 & 3.76 & 3.81 & 4.42 & 4.54 & 4.67 & 4.96 & 5.11 & 5.27 \\
\hline 2.0 & 50.00 & 0.21 & 0.80 & 188.80 & 3.70 & 1.56 & 3.72 & 3.81 & 3.91 & 4.53 & 4.62 & 4.74 & 5.11 & 5.25 & 5.37 \\
\hline 2.0 & 75.00 & 0.32 & 0.40 & 94.40 & 4.08 & 2.83 & 4.07 & 4.16 & 4.24 & 4.68 & 4.82 & 5.13 & 5.27 & 5.38 & 5.54 \\
\hline 2.0 & 75.00 & 0.32 & 0.60 & 141.60 & 4.08 & 2.29 & 4.12 & 4.25 & 4.37 & 4.75 & 5.00 & 5.23 & 5.41 & 5.54 & 5.74 \\
\hline 2.0 & 75.00 & 0.32 & 0.80 & 188.80 & 4.08 & 1.80 & 4.15 & 4.31 & 4.42 & 4.82 & 5.11 & 5.31 & 5.51 & 5.65 & 5.83 \\
\hline 2.0 & 100.00 & 0.42 & 0.40 & 94.40 & 4.50 & 3.14 & 4.40 & 4.58 & 4.75 & 5.23 & 5.37 & 5.49 & 5.78 & 5.97 & 6.12 \\
\hline 2.0 & 100.00 & 0.42 & 0.60 & 141.60 & 4.50 & 2.57 & 4.51 & 4.64 & 4.83 & 5.28 & 5.39 & 5.58 & 5.92 & 6.14 & 6.25 \\
\hline 2.0 & 100.00 & 0.42 & 0.80 & 188.80 & 4.50 & 2.05 & 4.58 & 4.71 & 4.89 & 5.32 & 5.46 & 5.67 & 5.98 & 6.21 & 6.32 \\
\hline 4.0 & 50.00 & 0.22 & 0.40 & 92.80 & 17.05 & 11.98 & 15.72 & 16.12 & 16.45 & 16.71 & 17.32 & 17.68 & 17.84 & 18.35 & 18.98 \\
\hline 4.0 & 50.00 & 0.22 & 0.60 & 139.20 & 17.05 & 9.62 & 15.49 & 15.98 & 16.15 & 15.34 & 15.72 & 16.12 & 16.82 & 17.24 & 17.98 \\
\hline 4.0 & 50.00 & 0.22 & 0.80 & 185.60 & 17.05 & 6.85 & 13.24 & 13.85 & 14.20 & 13.98 & 14.57 & 15.72 & 15.34 & 15.87 & 16.52 \\
\hline 4.0 & 75.00 & 0.32 & 0.40 & 92.80 & 18.92 & 13.30 & 17.68 & 18.12 & 18.45 & 18.44 & 19.78 & 19.82 & 20.12 & 20.55 & 20.88 \\
\hline 4.0 & 75.00 & 0.32 & 0.60 & 139.20 & 18.92 & 10.85 & 15.80 & 16.12 & 16.78 & 17.89 & 18.14 & 18.44 & 18.89 & 19.12 & 19.35 \\
\hline 4.0 & 75.00 & 0.32 & 0.80 & 185.60 & 18.92 & 8.08 & 14.12 & 14.89 & 15.14 & 15.89 & 16.15 & 17.12 & 16.98 & 18.12 & 19.34 \\
\hline 4.0 & 100.00 & 0.43 & 0.40 & 92.80 & 20.93 & 14.72 & 19.25 & 19.85 & 19.98 & 21.65 & 21.96 & 22.03 & 22.65 & 22.98 & 23.45 \\
\hline 4.0 & 100.00 & 0.43 & 0.60 & 139.20 & 20.93 & 12.16 & 17.98 & 18.24 & 18.45 & 19.35 & 19.98 & 20.65 & 20.68 & 21.12 & 22.65 \\
\hline 4.0 & 100.00 & 0.43 & 0.80 & 185.60 & 20.93 & 9.49 & 16.45 & 16.93 & 17.12 & 17.98 & 18.87 & 19.31 & 19.98 & 20.34 & 21.35 \\
\hline 6.0 & 50.00 & 0.22 & 0.40 & 91.20 & 36.53 & 26.22 & 32.10 & 33.12 & 34.08 & 34.87 & 35.01 & 36.17 & 36.98 & 37.41 & 38.12 \\
\hline 6.0 & 50.00 & 0.22 & 0.60 & 136.80 & 36.53 & 20.59 & 29.12 & 29.98 & 30.45 & 30.98 & 31.79 & 32.67 & 32.98 & 34.12 & 35.23 \\
\hline 6.0 & 50.00 & 0.22 & 0.80 & 182.40 & 36.53 & 14.63 & 26.98 & 27.36 & 28.14 & 28.24 & 29.14 & 30.78 & 30.19 & 32.39 & 33.78 \\
\hline 6.0 & 75.00 & 0.33 & 0.40 & 91.20 & 42.16 & 29.27 & 37.89 & 39.43 & 41.32 & 39.64 & 41.56 & 42.65 & 41.32 & 43.17 & 44.18 \\
\hline 6.0 & 75.00 & 0.33 & 0.60 & 136.80 & 42.16 & 23.47 & 34.85 & 36.12 & 37.86 & 36.56 & 37.86 & 39.89 & 39.34 & 41.76 & 42.12 \\
\hline 6.0 & 75.00 & 0.33 & 0.80 & 182.40 & 42.16 & 16.98 & 31.87 & 32.51 & 33.24 & 34.58 & 35.84 & 36.59 & 36.42 & 38.12 & 40.17 \\
\hline 6.0 & 100.00 & 0.44 & 0.40 & 91.20 & 47.13 & 32.68 & 42.87 & 43.12 & 44.67 & 45.23 & 46.11 & 48.03 & 47.87 & 48.56 & 50.01 \\
\hline 6.0 & 100.00 & 0.44 & 0.60 & 136.80 & 47.13 & 26.56 & 39.12 & 40.67 & 41.34 & 42.89 & 43.23 & 44.43 & 45.67 & 46.33 & 47.34 \\
\hline 6.0 & 100.00 & 0.44 & 0.80 & 182.40 & 47.13 & 19.99 & 35.87 & 36.76 & 37.23 & 38.43 & 40.14 & 41.12 & 42.68 & 43.02 & 44.12 \\
\hline
\end{tabular}


Table 10

Statistical analysis for the comparison of the strength reduction factor for offset web holes

\begin{tabular}{ll}
\hline Statistical parameters & $R_{O S H}\left[\right.$ Test\& FEA] $/ R_{P(O S H)}\left[0.98-0.11(a / h)+0.01(x / h)+0.05\left(r_{q} / t\right)+0.41(q / h)\right]$ \\
\hline Mean, $P_{\mathrm{m}}$ & 1.00 \\
Coefficient of variation, $V_{\mathrm{p}}$ & 0.06 \\
Reliability index, $\beta$ & 2.81 \\
Resistance factor, $\phi$ & 0.85 \\
\hline
\end{tabular}

Table 11

Statistical analysis for the comparison of the strength reduction factor for down web holes

\begin{tabular}{ll}
\hline Statistical parameters & $R_{C S H}[$ Test\& FEA $] / R_{P(C S H)}\left[0.92-0.35(a / h)+0.12(N / h)+0.21\left(r_{q} / t\right)+0.22(q / h)\right]$ \\
\hline Mean, $P_{\mathrm{m}}$ & 1.00 \\
Coefficient of variation, $V_{\mathrm{p}}$ & 0.06 \\
Reliability index, $\beta$ & 2.78 \\
Resistance factor, $\phi$ & 0.85 \\
\hline
\end{tabular}




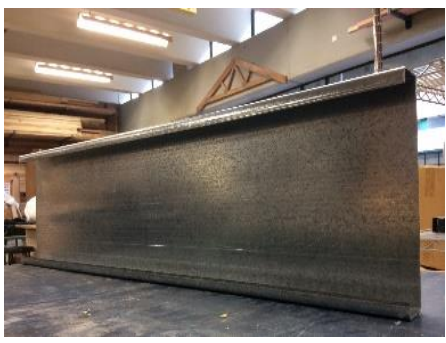

(a) Plain webs

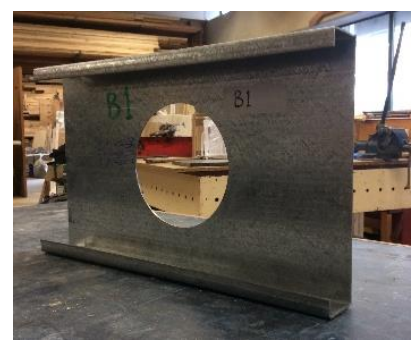

(b) With unstiffened holes

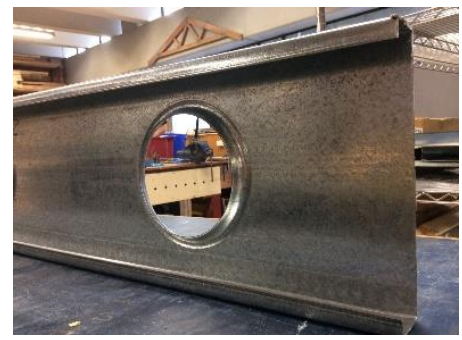

(c) With edge-stiffened holes

Fig.1 CFS channel sections

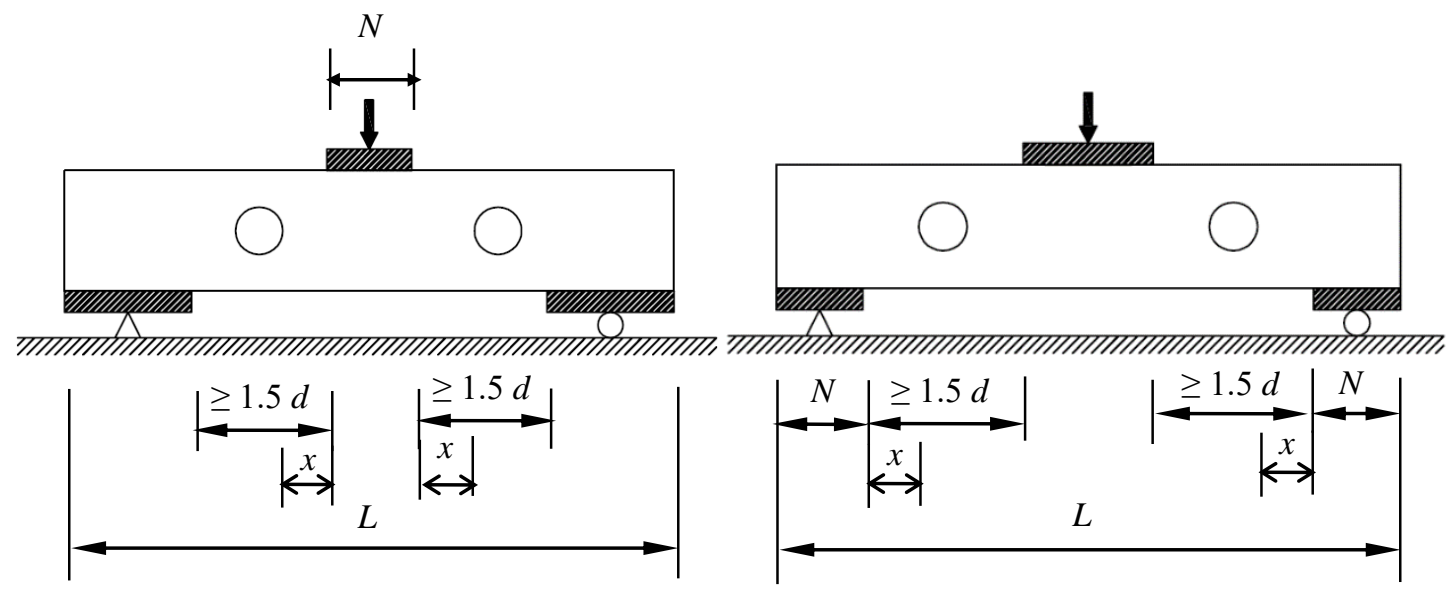

(a) IOF

(b) $\mathrm{EOF}$

Fig.2 IOF and EOF loading conditions with offset web holes studied by Uzzaman et al. [6] 


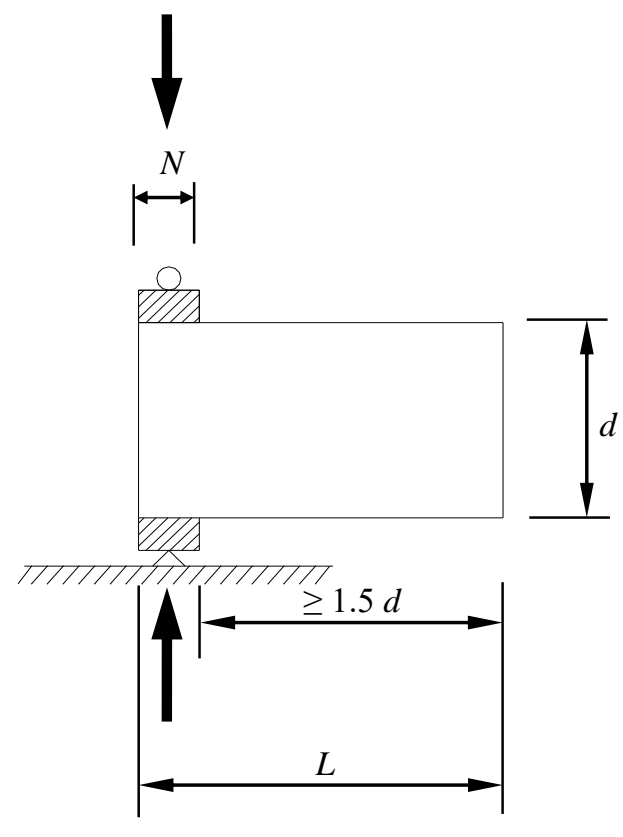

(a) Plain webs

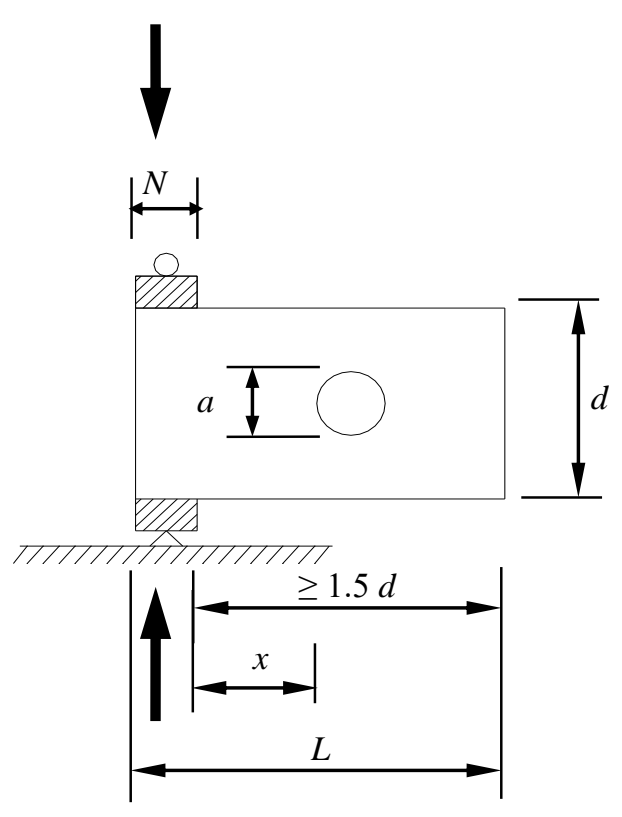

(b) With offset holes

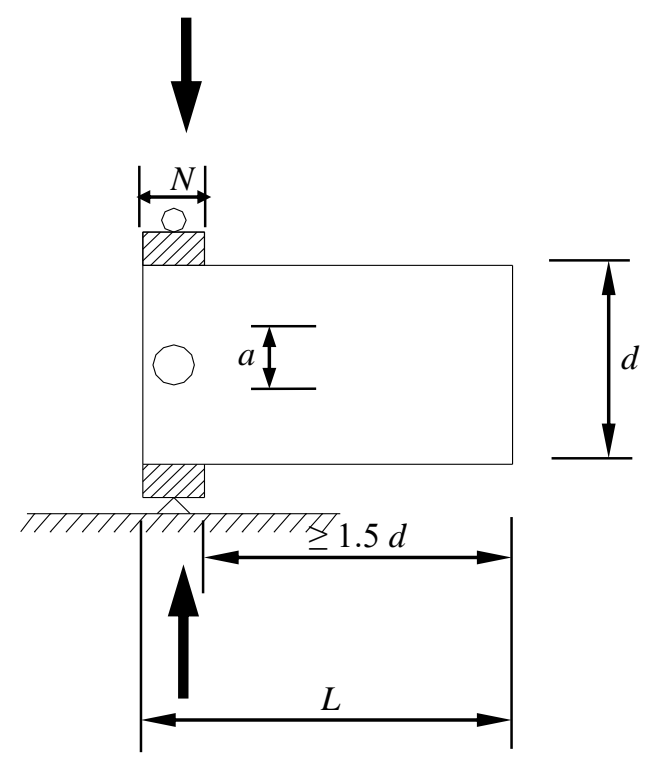

(c) With down holes

Fig.3 ETF loading condition 

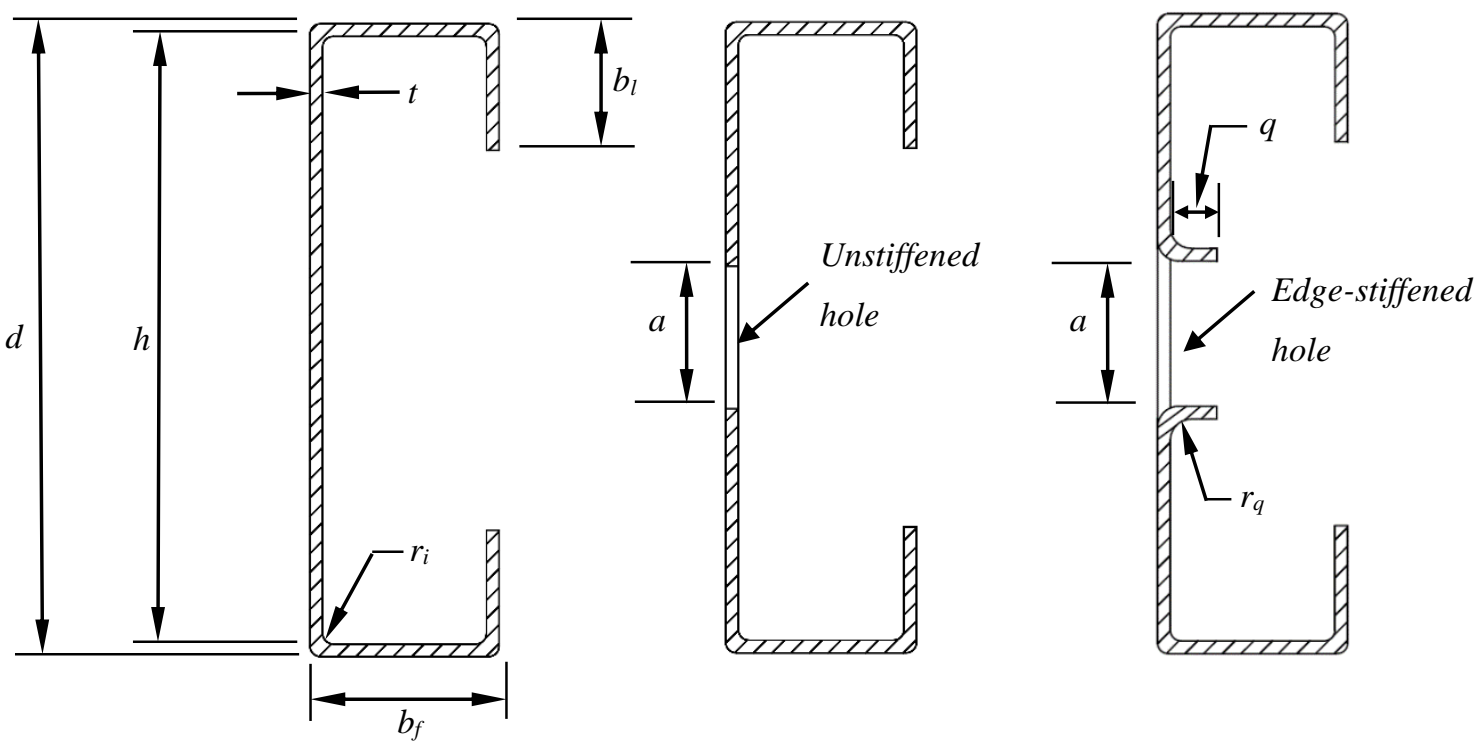

(a) Plain web

(b) Unstiffened holes

(c) Edge-stiffened holes

Fig.4 Definition of symbols 


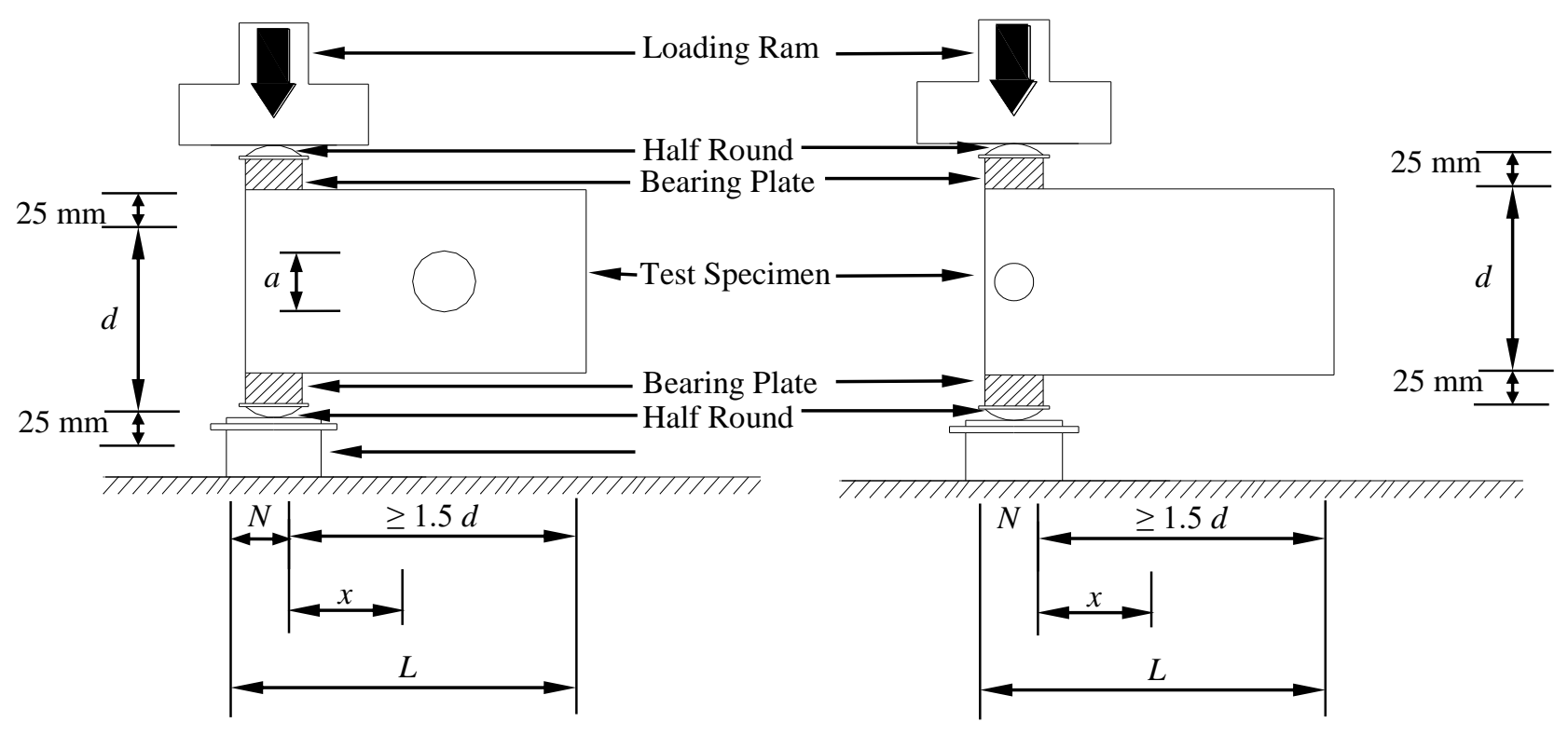

(a) Web hole with a horizontal clear distance to the near edge of bearing plate

(b) Web hole down the bearing plate 


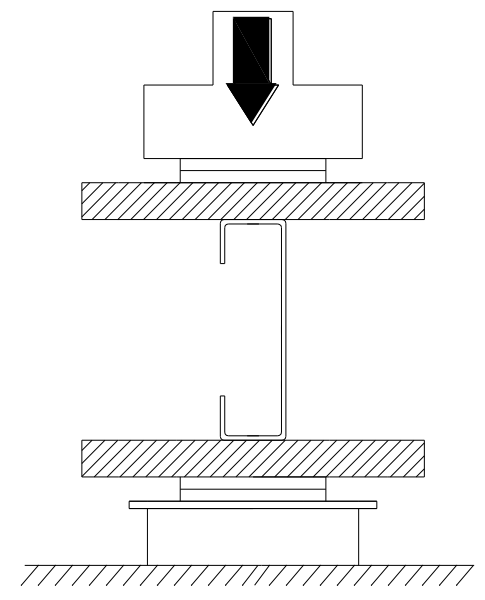

(c) End view

Fig.5 Schematic view of test set-up for ETF loading condition 


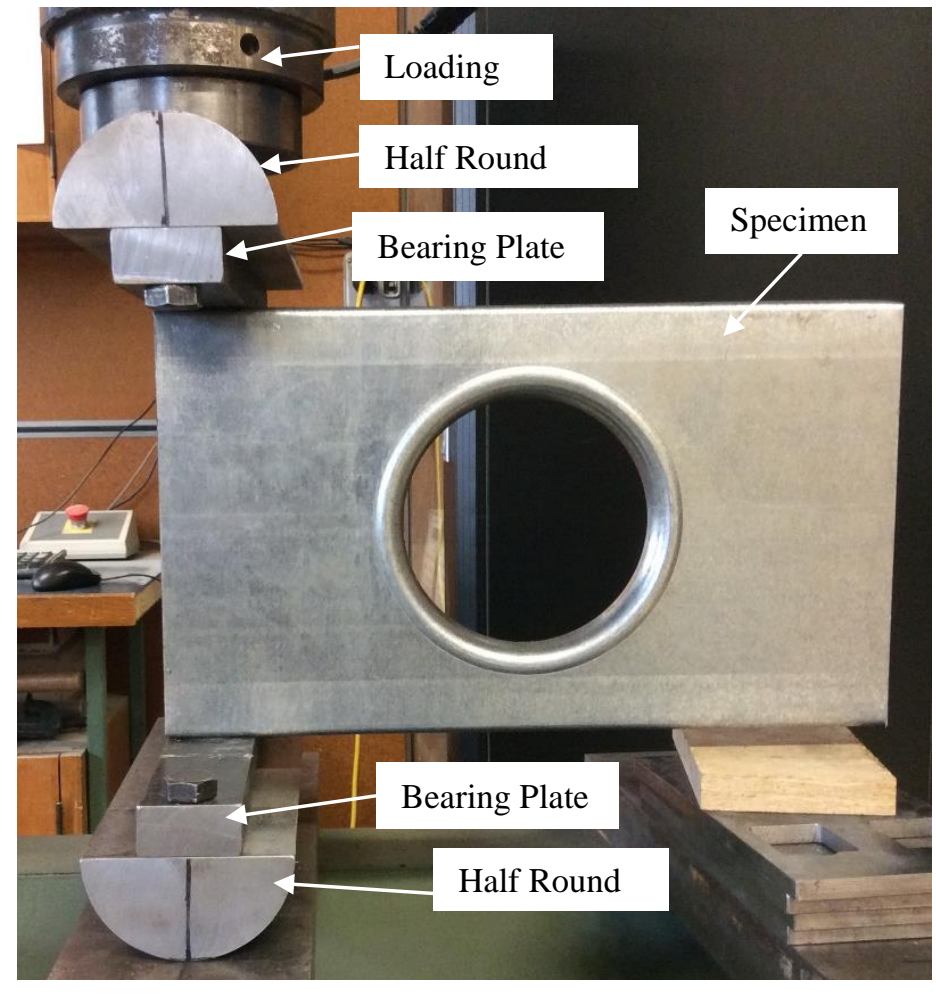

(a) Experimental

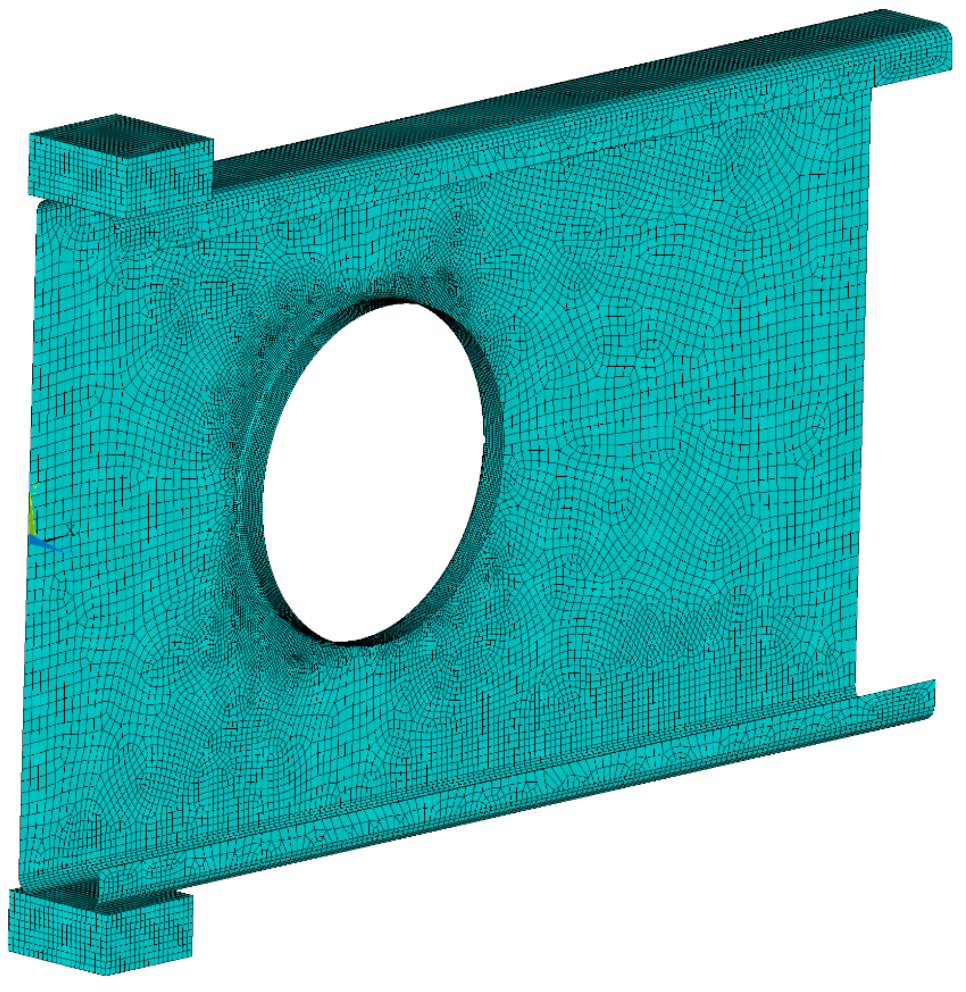

(b) FEA

Fig.6 Comparison of experiment and finite element analysis for offset web hole 


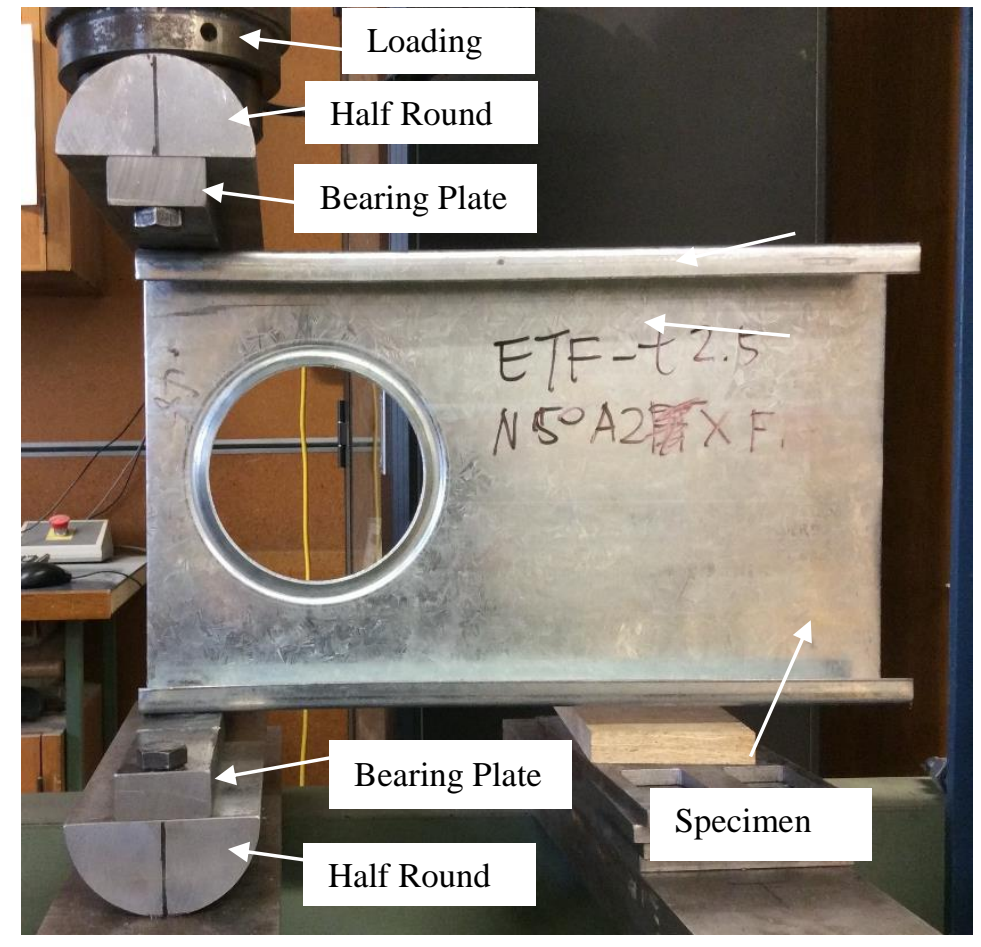

(a) Experimental

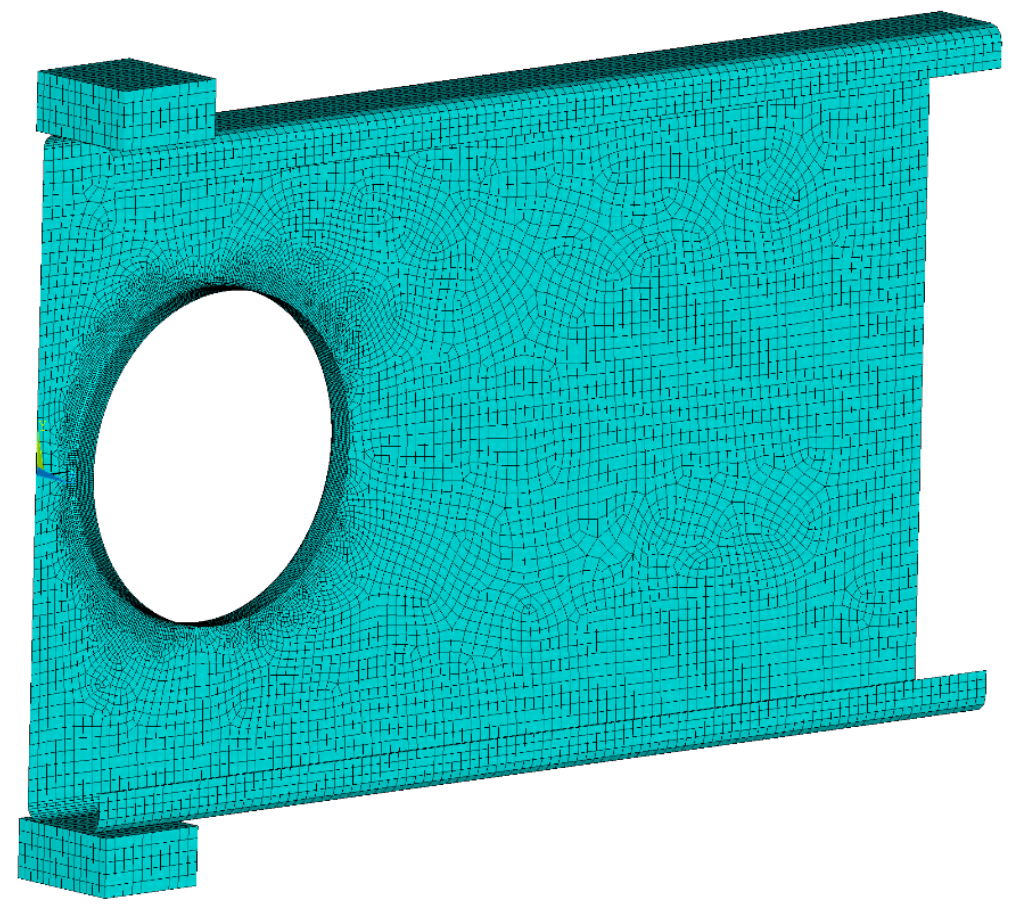

(b) FEA

Fig.7 Comparison of experiment and finite element analysis for down web hole 

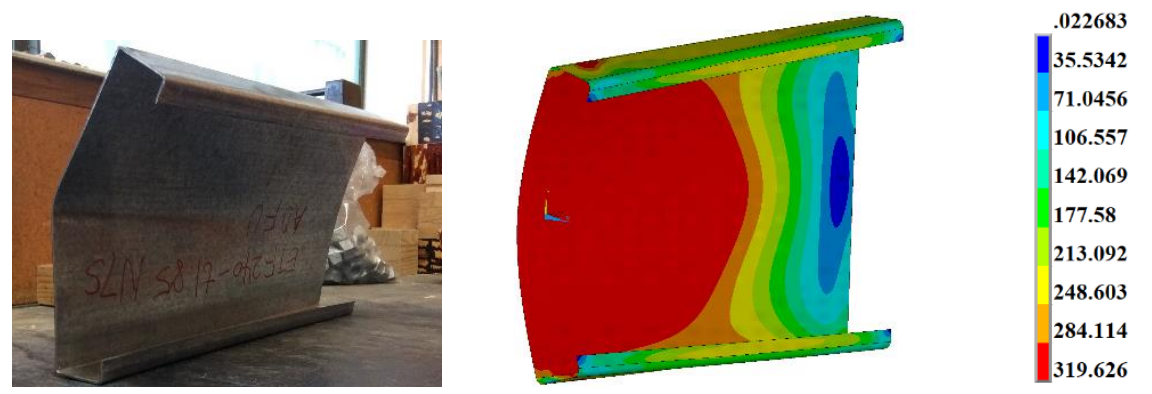

(a) Comparison of deformation shape for without holes
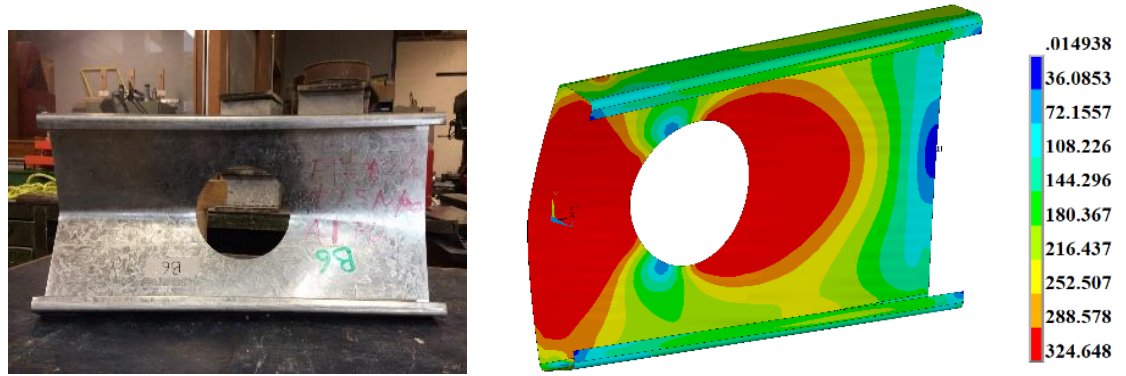

(b) Comparison of deformation shape for offset unstiffened hole
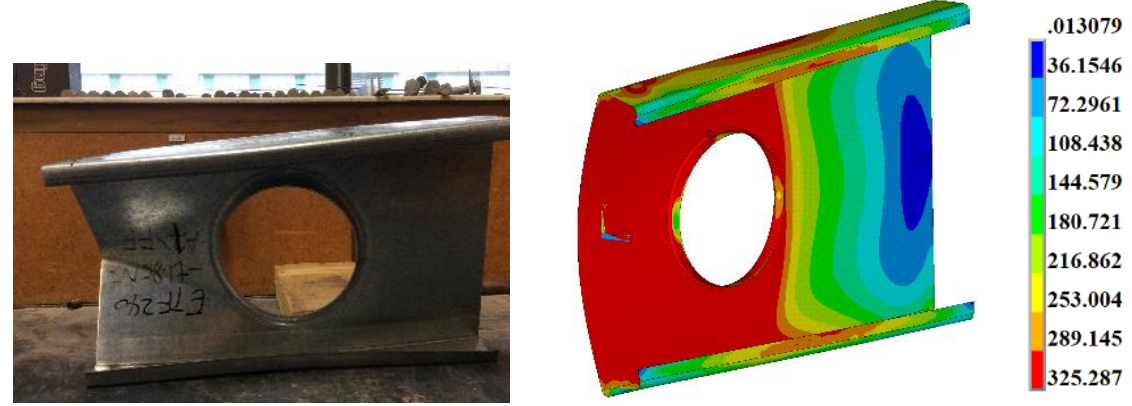

(c) Comparison of deformation shape for offset edge-stiffened hole
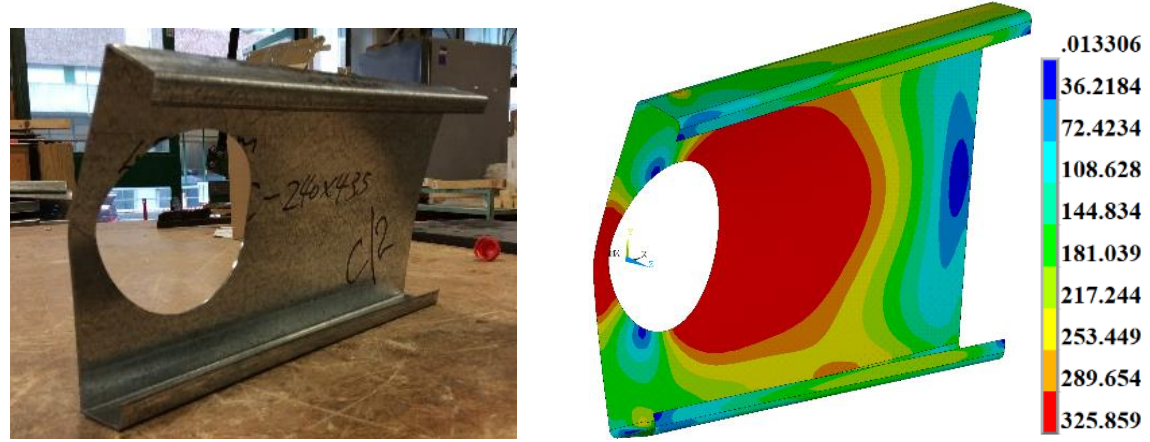

(d) Comparison of deformation shape for down unstiffened hole
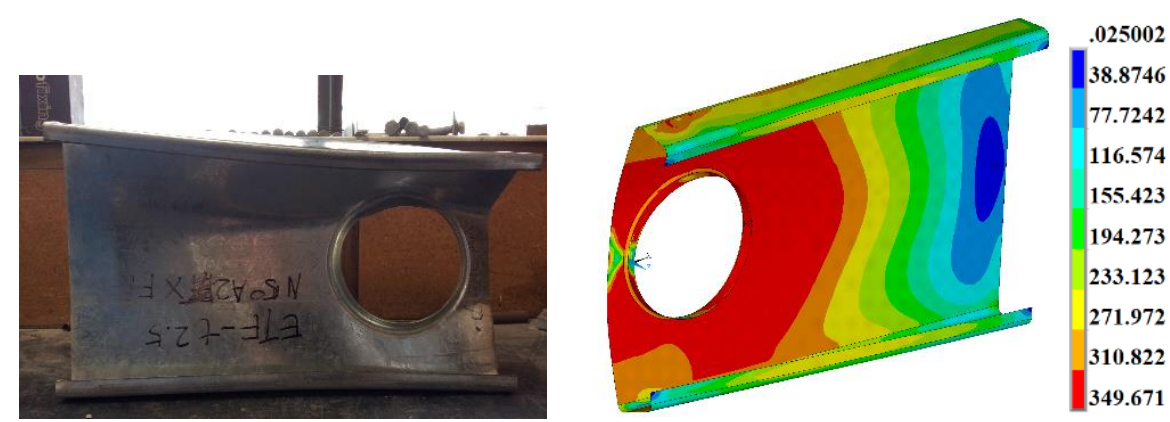

(e) Comparison of deformation shape for down edge-stiffened hole

Fig.8 Comparison of the deformation shape for ETF loading condition 


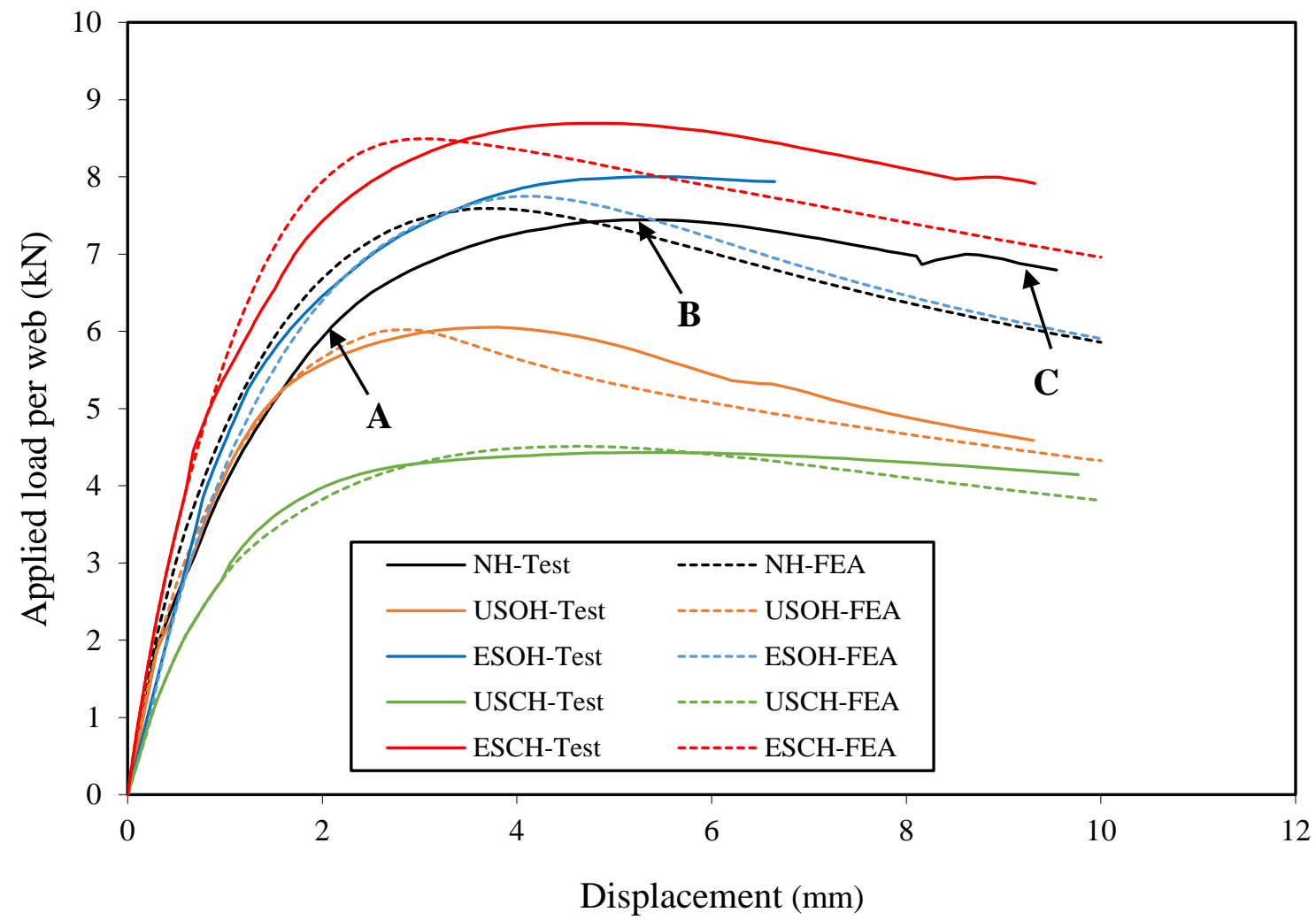

Fig.9 Comparison of web deformation curves for specimen $290 \times 45 \times 15-\mathrm{t} 2.5 \mathrm{~N} 75$

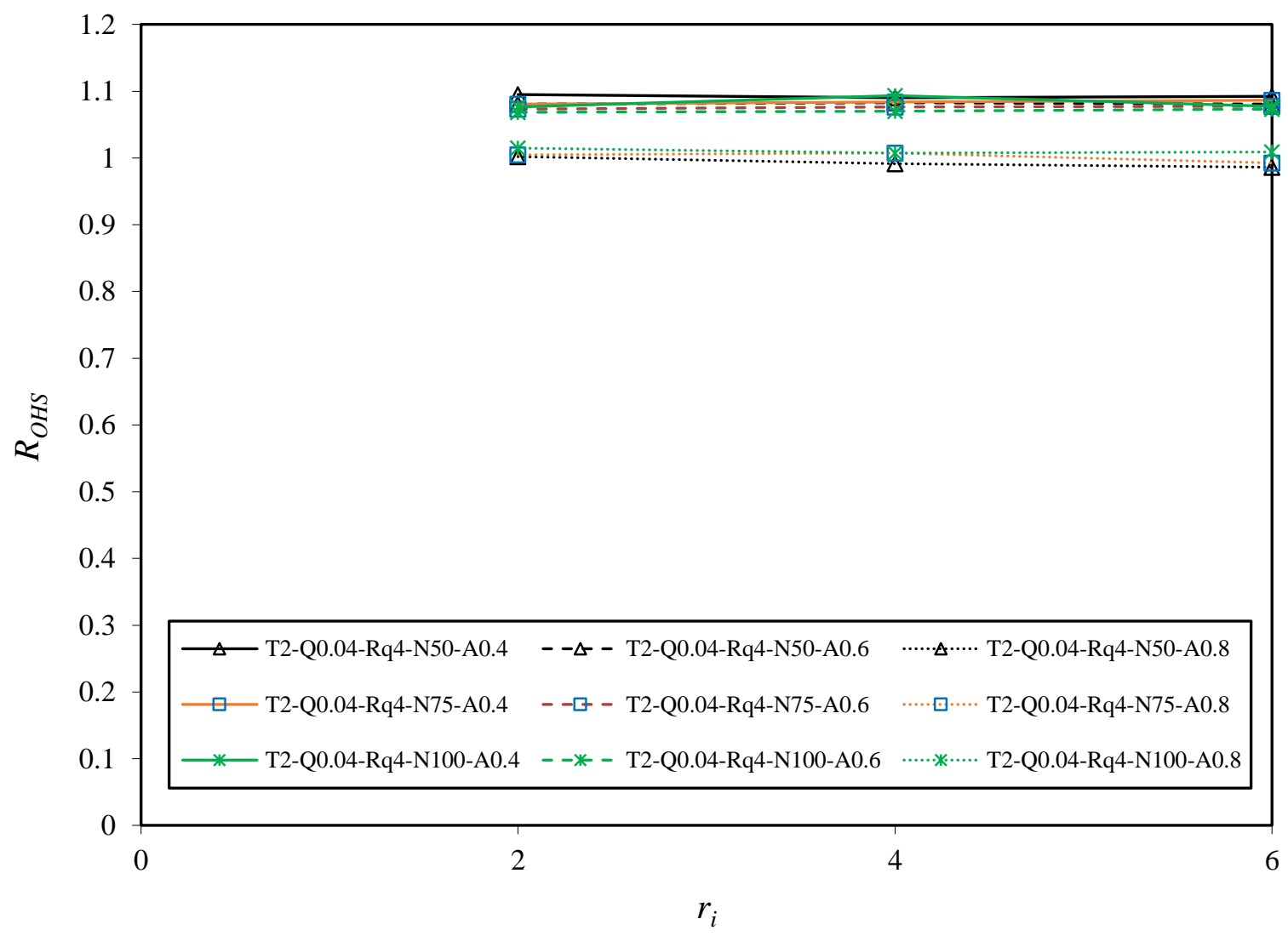

Fig.10 Variation in reduction factors with sizes of corner radii $\left(\mathrm{r}_{\mathrm{i}}\right)$ for offset web holes 


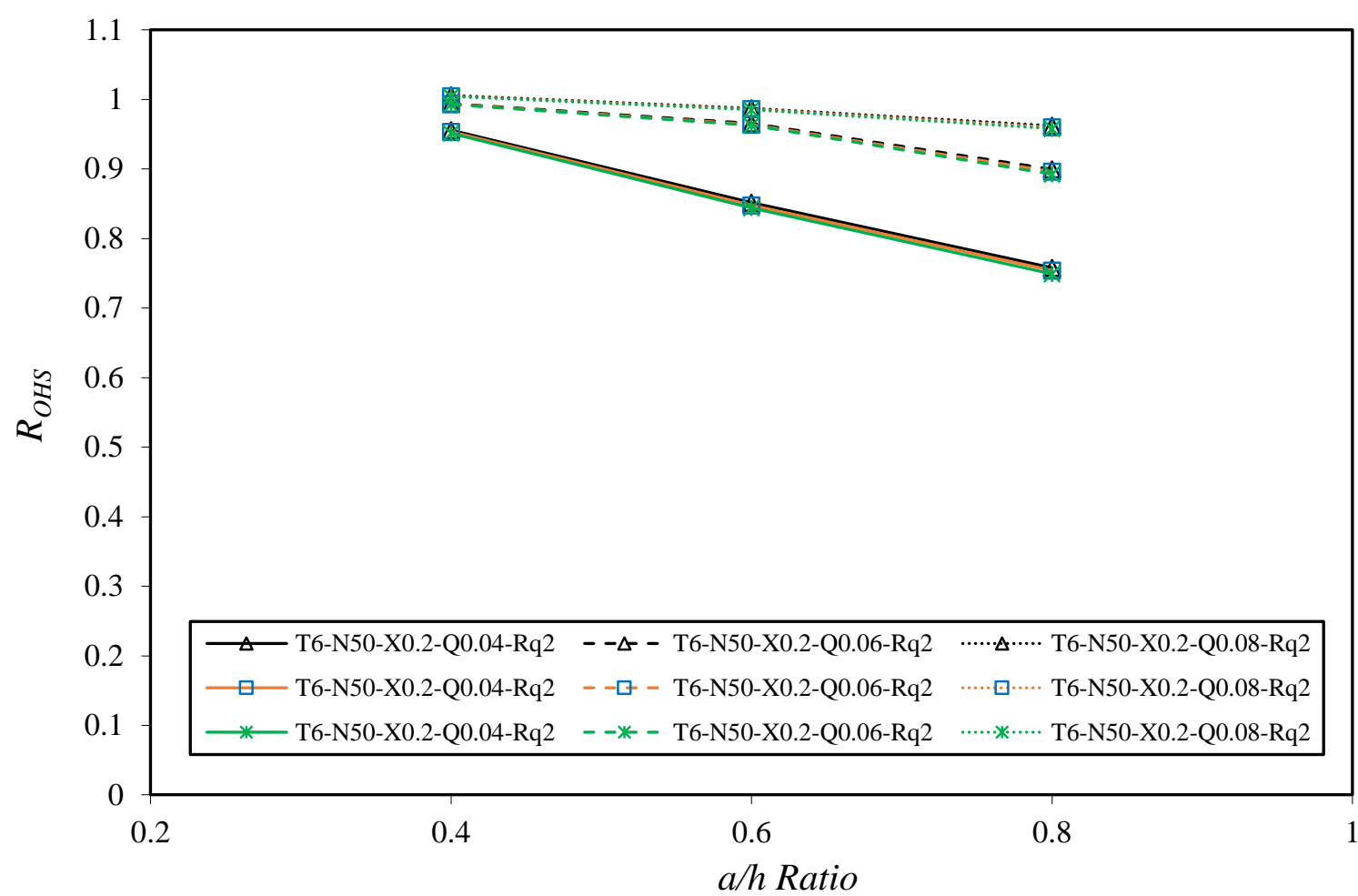

(a) Variation in reduction factor with $a / h$ for T6-N50-X0.2

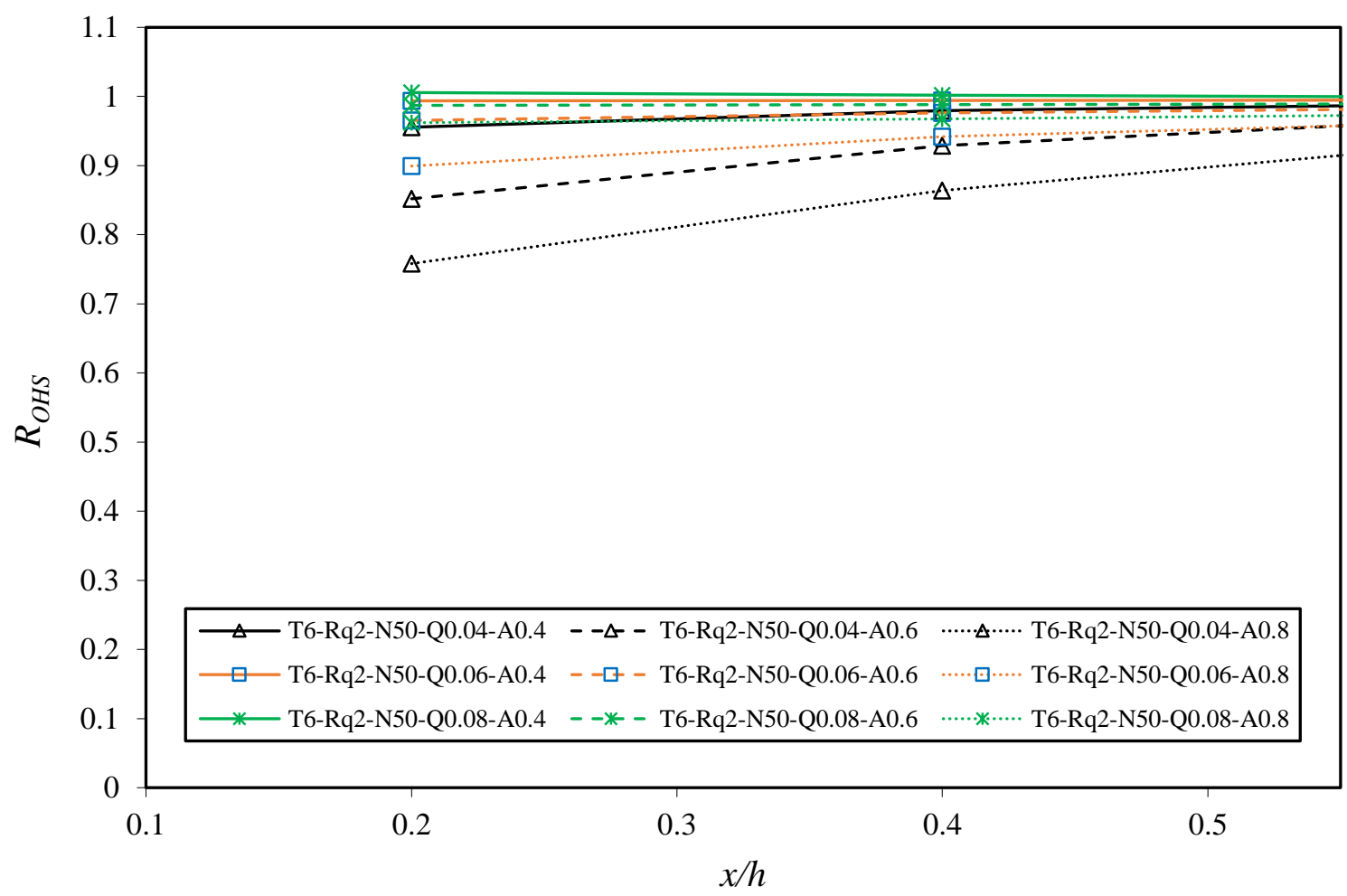

(b) Variation in reduction factor with $x / h$ for T6-Rq2-N50

Fig. 11 Variation in reduction factors with $a / h$ and $x / h$ for offset web holes 


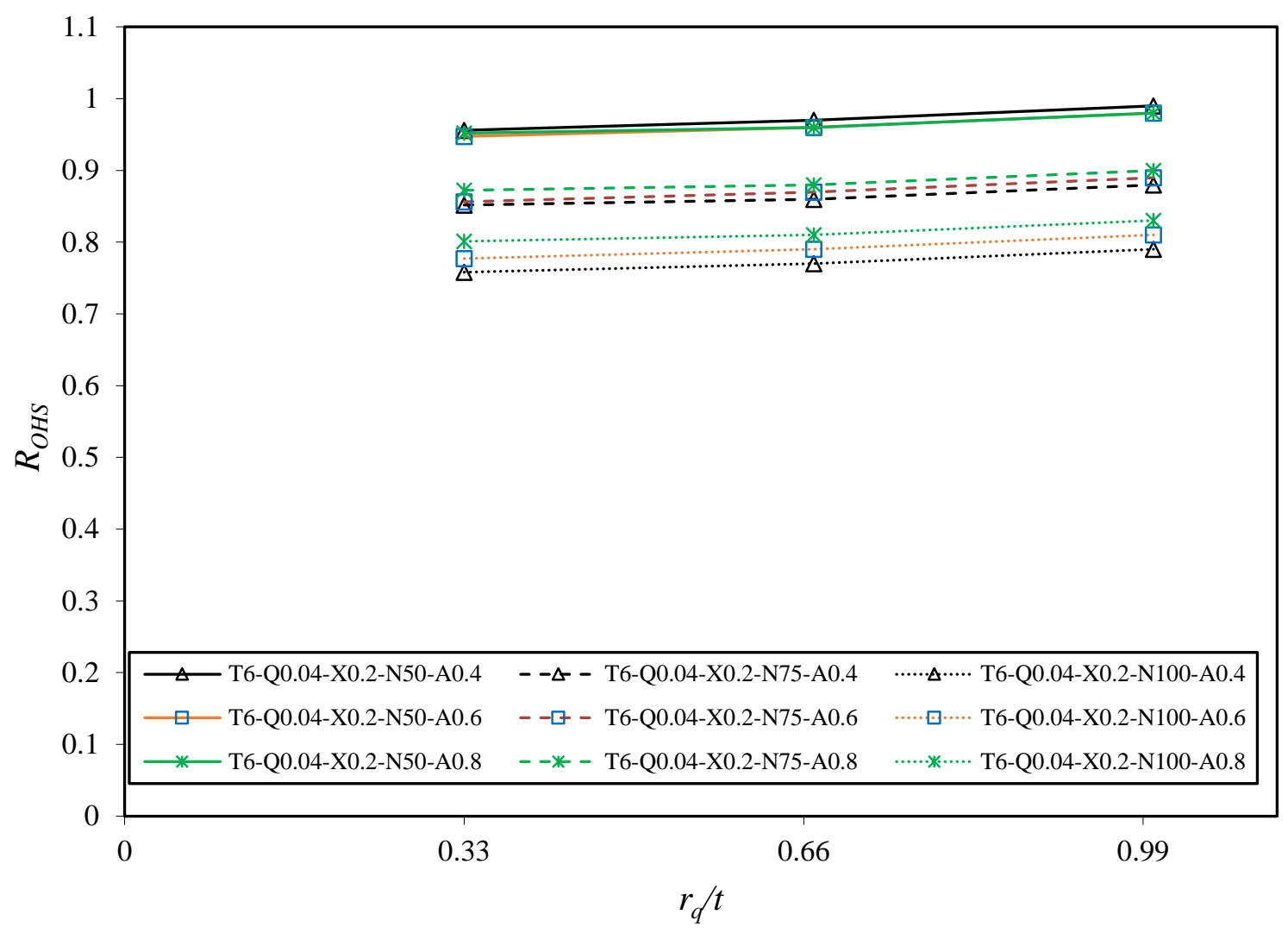

(a) Variation in reduction factor with $r_{q} / t$ for T6-Q0.04

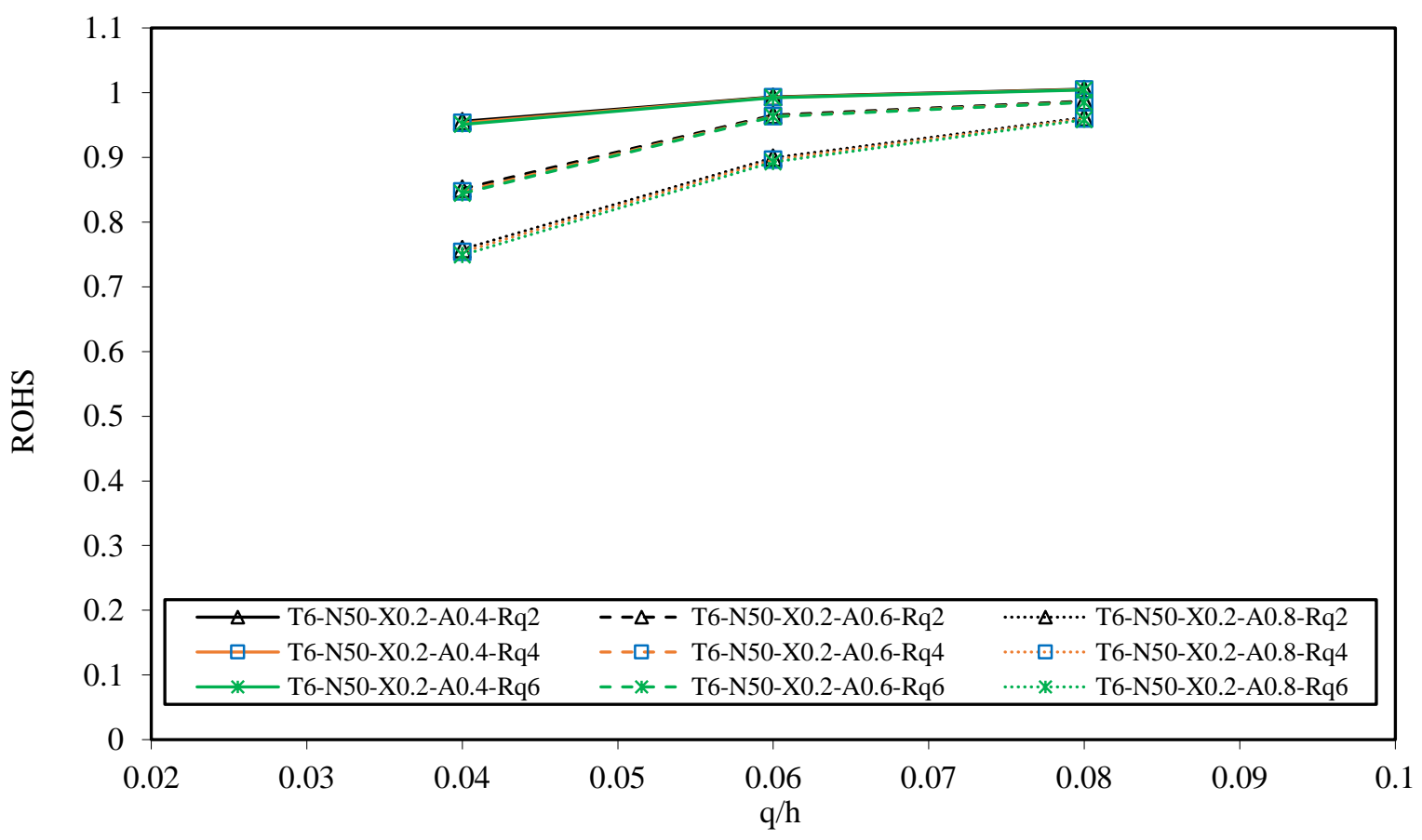

(b) Variation in reduction factor with $q / h$ for T6-N50-X0.2

Fig.12 Variation in reduction factors with $r_{q} / t$ and $q / h$ for offset web holes 


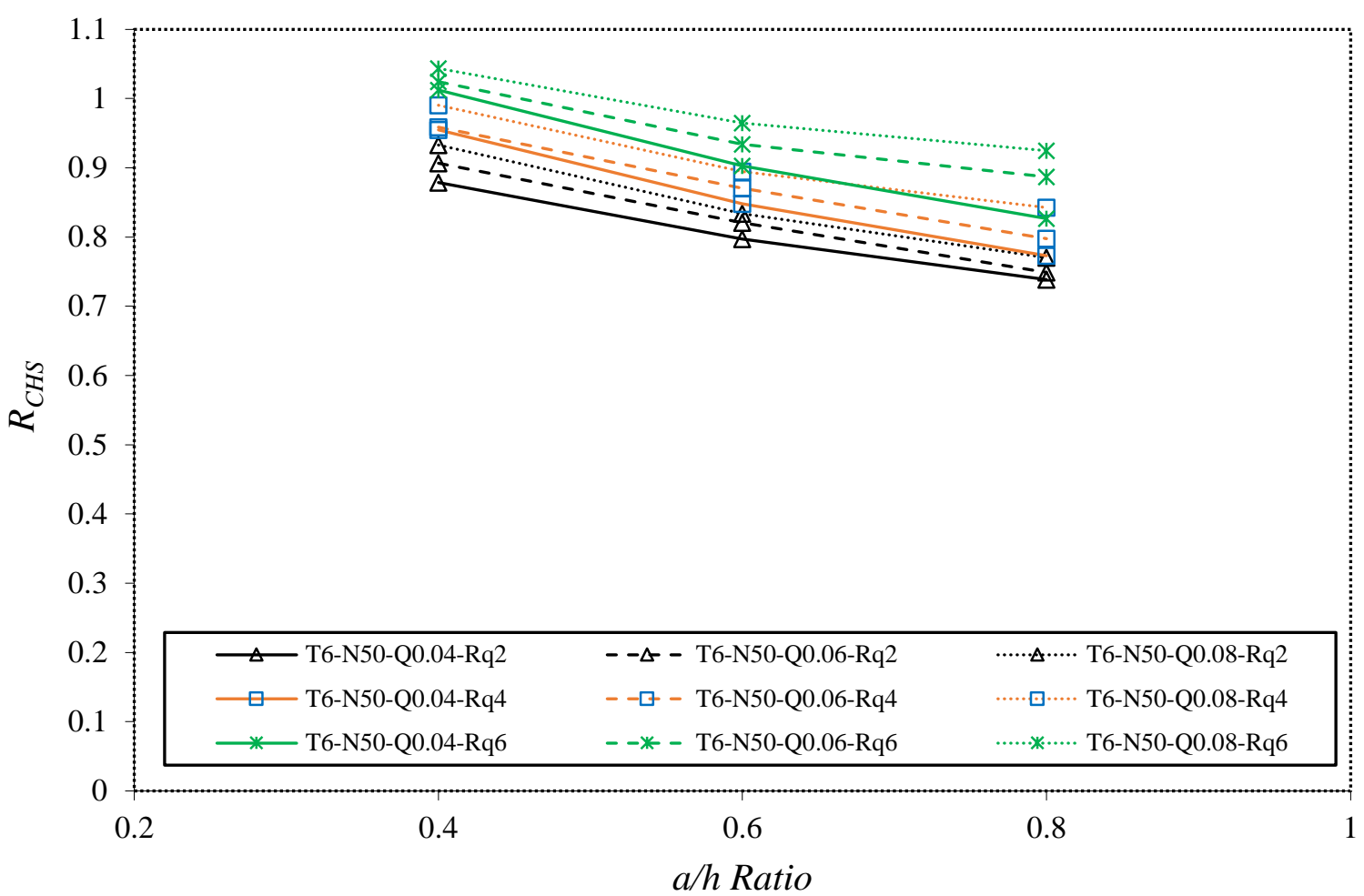

(a) Variation in reduction factor with $a / h$ for T6-N50

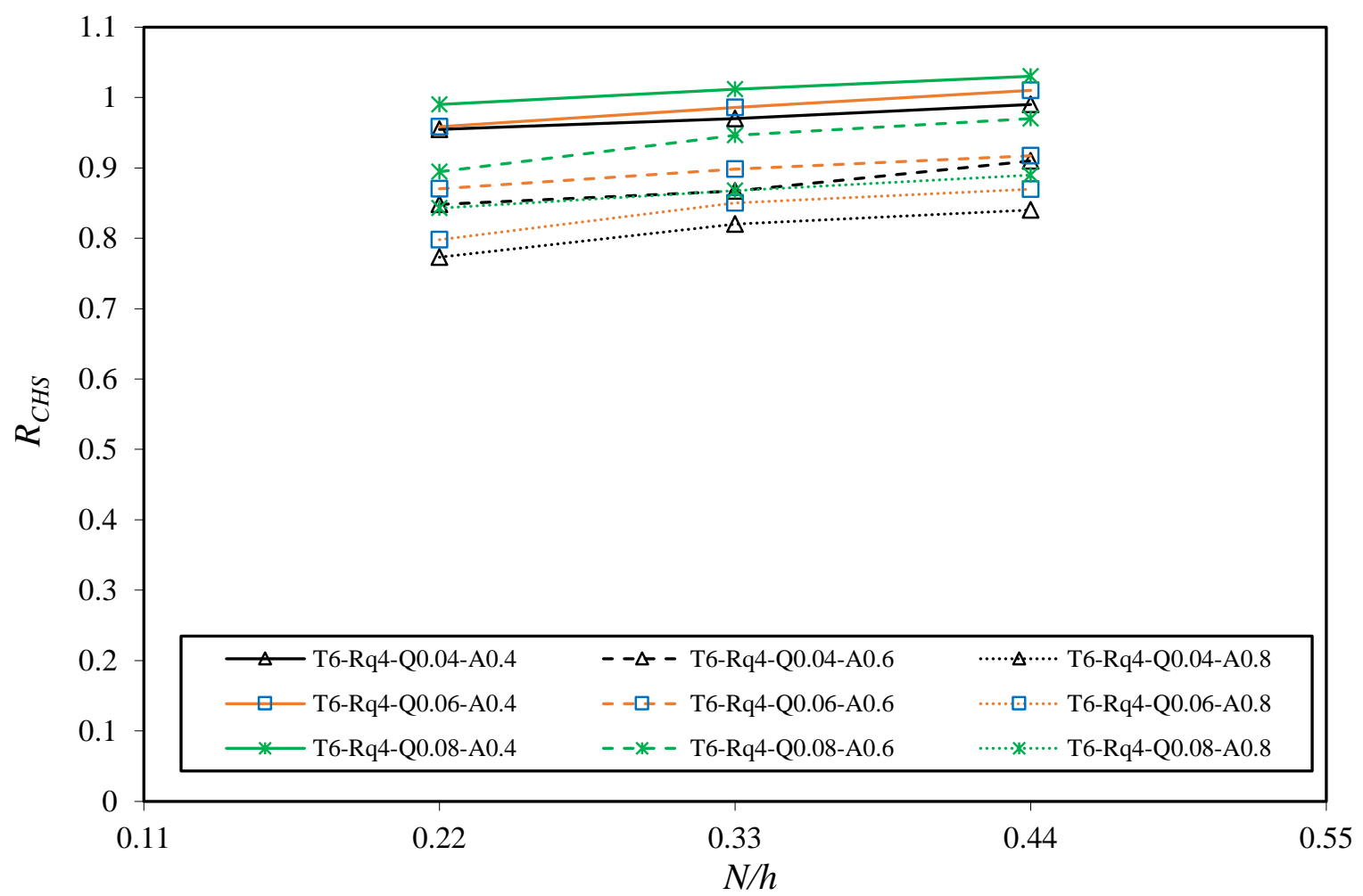

(b) Variation in reduction factor with $N / h$ for T6-Rq4

Fig.13 Variation in reduction factors with $a / h$ and $\mathrm{N} / \mathrm{h}$ for down web holes 


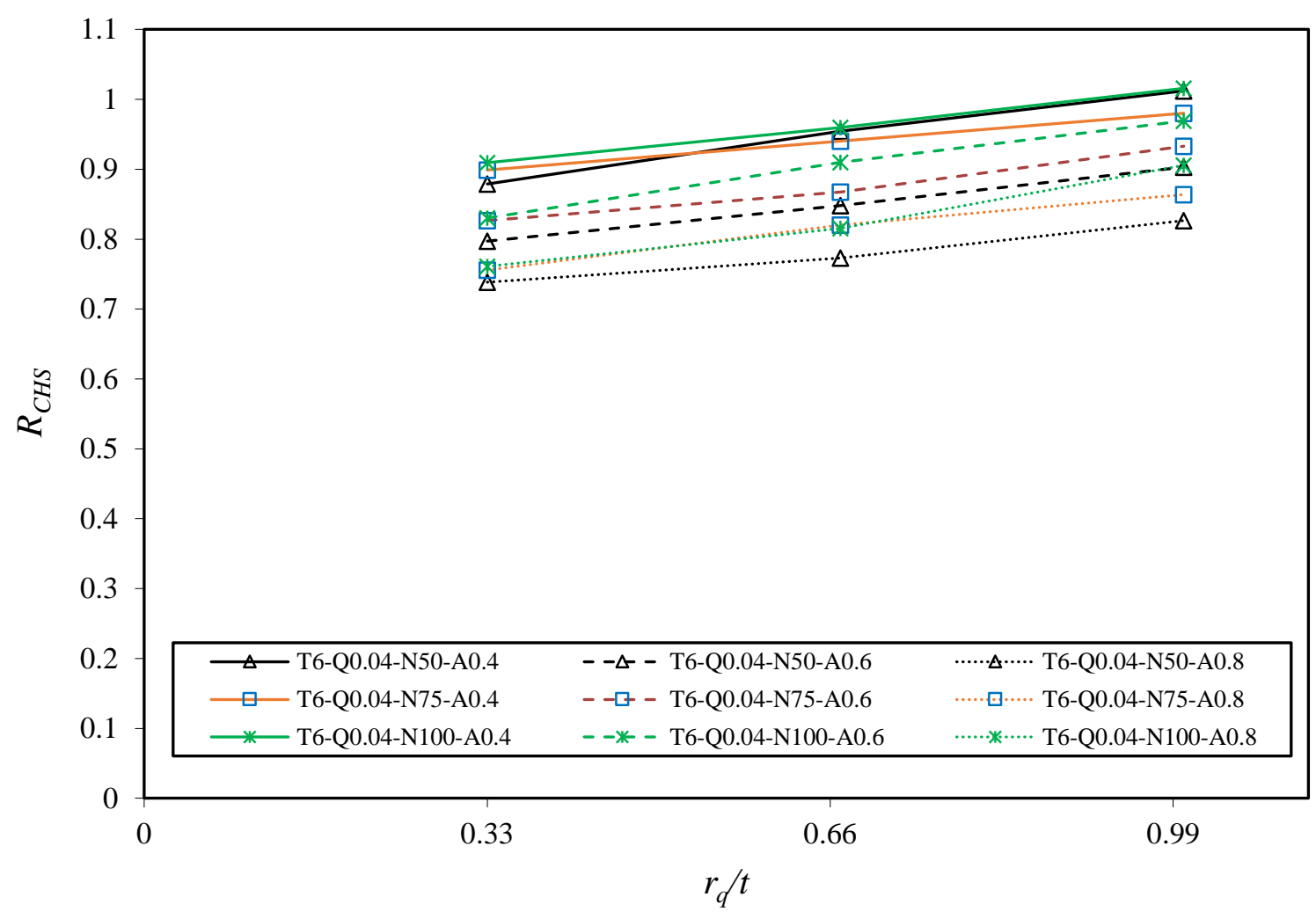

(a) Variation in reduction factor with $r_{q} / t$ for T6-Q0.04

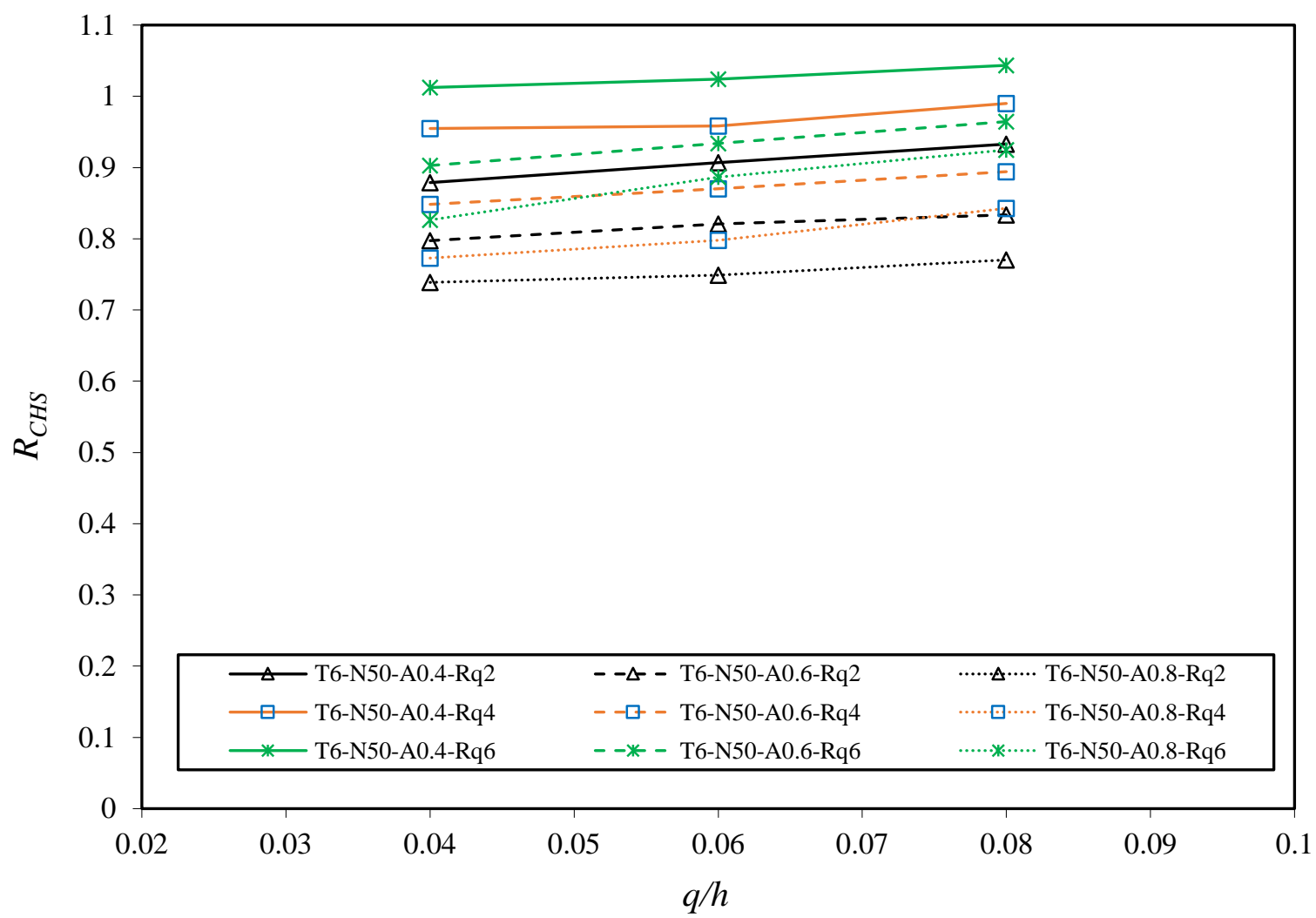

(b) Variation in reduction factor with $q / h$ for T6-N50

Fig.14 Variation in reduction factors with $r_{q} / t$ and $q / h$ for down web holes 


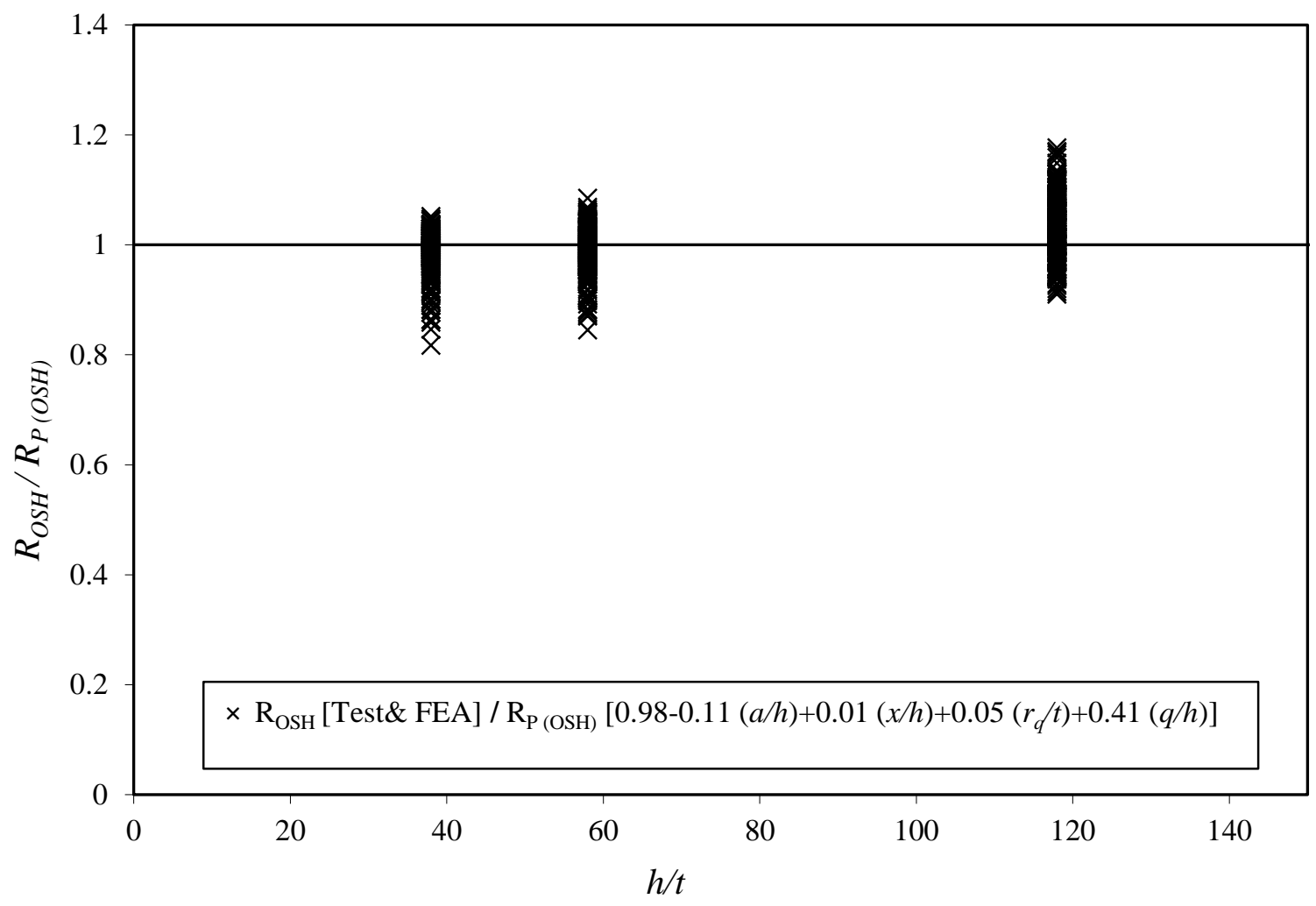

Fig.15 Comparison of the reduction factors for web holes offset to bearing plate

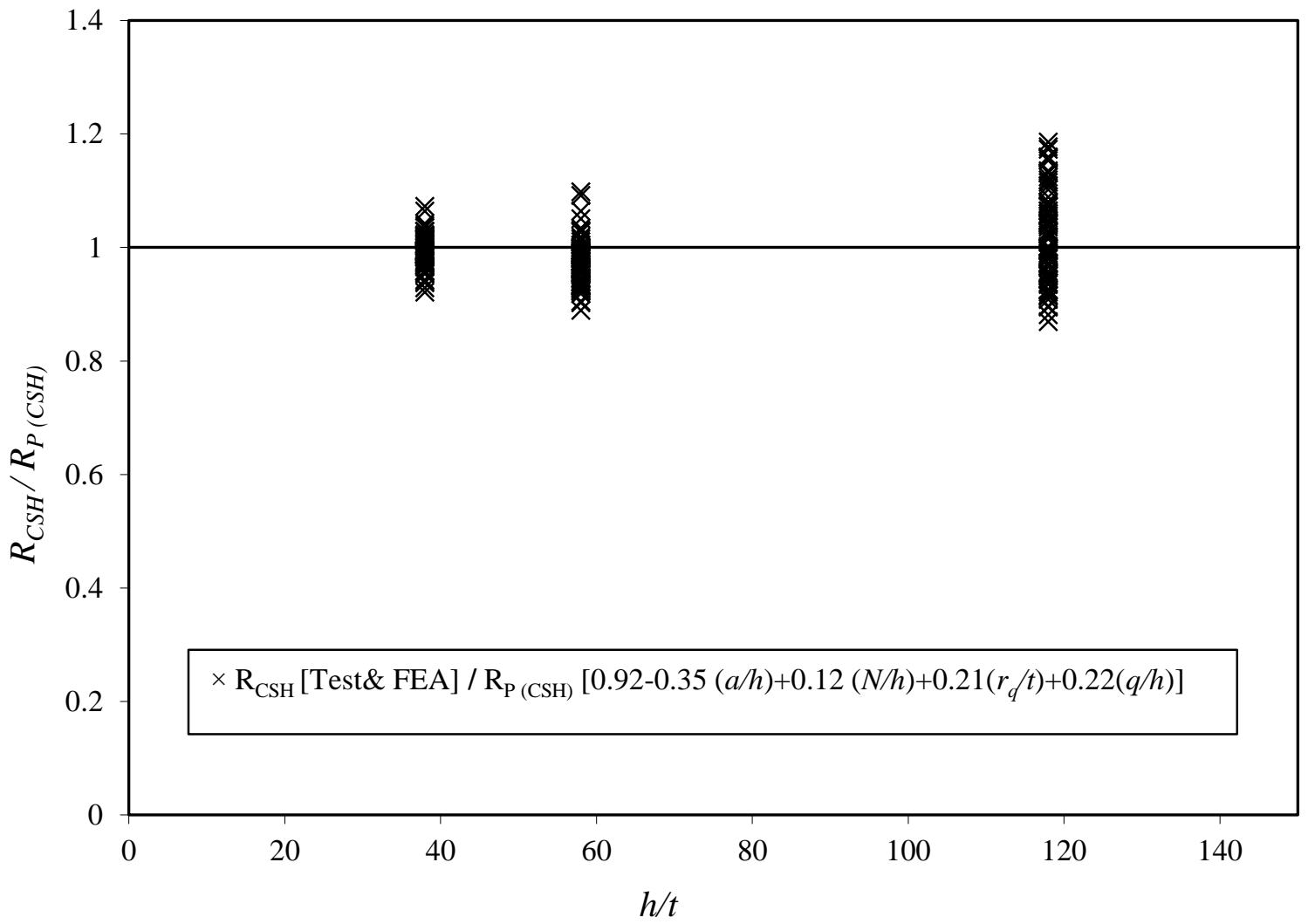

Fig.16 Comparison of the reduction factors for web holes down the bearing plate 